\title{
Silane Ligand Exchange to Make Hydrophobic Superparamagnetic Nanoparticles Water-Dispersible
}

\author{
Randy De Palma, ${ }^{*},+, \downarrow$ Sara Peeters, ${ }^{\dagger}$ Margriet J. Van Bael, ${ }^{\S}$ Heidi Van den Rul,,${ }^{\perp, \#}$ \\ Kristien Bonroy, ${ }^{\dagger}$ Wim Laureyn,${ }^{\dagger}$ Jules Mullens, ${ }^{\perp}$ Gustaaf Borghs,${ }^{\dagger}$ and Guido Maes ${ }^{\ddagger}$ \\ IMEC, MCP-ART, Kapeldreef 75, B-3001 Leuven, Belgium, Physical and Quantum Chemistry, Catholic \\ University Leuven, Celestijnenlaan 200F, 3001 Leuven, Belgium, Solid State Physics and Magnetism, \\ Catholic University Leuven, Celestijnenlaan 200D, 3001 Leuven, Belgium, Laboratory of Inorganic and \\ Physical Chemistry, Institute for Materials Research, Hasselt University, Agoralaan Building D, 3590 \\ Diepenbeek, Belgium, and IMEC division IMOMEC, Agoralaan Building D, 3590 Diepenbeek, Belgium
}

\section{Received November 23, 2006. Revised Manuscript Received January 19, 2007}

\begin{abstract}
Ferrite magnetic nanoparticles (MNPs) were functionalized with a variety of silanes bearing different functional endgroups to render them stable with respect to aggregation and keep them well-dispersed in aqueous media. The MNPs were prepared by the thermal decomposition method, widely used for the synthesis of monodisperse nanoparticles with controllable size. This method makes use of a hydrophobic surfactant to passivate the surface, which results in nanoparticles that are solely dispersible in nonpolar solvents. For use in biological applications, these nanoparticles need to be made water-dispersible. Therefore, a new procedure was developed on the basis of the exchange of the hydrophobic surface ligands with silanes bearing different endgroups to decorate ferrite magnetic nanoparticles with diverse functionalities . By this means, we could easily determine the influence of the endgroup on the nanoparticle stability and water-dispersibility. Amino-, carboxylic acid- and poly(ethylene glycol)-terminated silanes were found to render the MNPs highly stable and water-dispersible because of electrostatic and/or steric repulsion. The silane molecules were also found to form a protective layer against mild acid and alkaline environments. The ligand exchange on the nanoparticle surface was thoroughly characterized using SQUID, TEM, XPS, DLS, TGA, FTIR, UV-vis, and zeta potential measurements. The presented approach provides a generic strategy to functionalize magnetic ferrite nanoparticles and to form stable dispersions in aqueous media, which facilitates the use of these magnetic nanoparticles in biological applications.
\end{abstract}

\section{Introduction}

The biological application of magnetic nanoparticles (MNPs) is of growing importance in biotechnology. Magnetic nanoparticles have numerous applications in biomagnetic separation, ${ }^{1}$ magnetic biosensing, ${ }^{2,3}$ magnetic resonance imaging, ${ }^{4,5}$ (MRI) and hyperthermia treatment. ${ }^{6,7}$ To apply nanoparticles in these fields, it is important to accurately control the size, shape, and (bio)chemical coating and to retain the thermal and chemical stability of the nanoparticles. As the size of the particles decreases, it is known that the surface effect becomes more significant because of an increase in the fraction of surface atoms vs bulk atoms. In most of their potential applications, the quality and structure

\footnotetext{
* Corresponding author. Phone: 32-16-281083. Fax: 32-16-281097. Randy.Depalma@imec.be.

$\dagger$ IMEC, MCP-ART.

¥ Physical and Quantum Chemistry, Catholic University Leuven.

$\S$ Solid State Physics and Magnetism, Catholic University Leuven.

${ }^{\perp}$ Institute for Materials Research, Hasselt University.

\# IMEC division IMOMEC.

(1) Šafařík, I.; Šafaříková, M. Biomagn. Res. Technol. 2004, $2,7$.

(2) Megens, M.; Prins, M. J. Magn. Magn. Mater. 2005, 293, 702.

(3) Graham, D. L.; Ferreira, H. A.; Freitas, P. P. Trends Biotechnol. 2004, $22,455$.

(4) Neuberger, T.; Schöpf, B.; Hofmann, H.; Hofmann, M.; von Rechenberg, B. J. Magn. Magn. Mater. 2005, 293, 483.

(5) Berry, C.; Curtis, A. S. G. J. Phys. D: Appl. Phys. 2003, 36, R198.

(6) Gupta, A. K.; Gupta, M. Biomaterials 2005, 26, 3995.

(7) Mornet, S.; Vasseur, S.; Grasset, F.; Duguet, E. J. Mater. Chem. 2004 $14,2161$.
}

of the nanoparticles' surface will undoubtly play a pivotal role in determining their function. ${ }^{8}$ Therefore, a key challenge for future bioapplications of MNPs is the development of surface chemistry that provides a versatile, stable, and welldefined interface while facilitating the incorporation of chemical functional groups. A general route that simultaneously addresses these issues could be of vital importance.

The useful magnetic properties of ferrite MNPs have recently inspired synthetic advances that result in monodisperse particles with tunable sizes. ${ }^{9}$ Several magnetic oxides have been synthesized using microemulsion, coprecipitation, and other water-based methods. ${ }^{6,10}$ The disadvantage of these aqueous solution syntheses is that the nanoparticle quality, more specifically their size uniformity and crystallinity, is rather poor. Recently, new synthetic procedures have been developed to obtain scalable preparative routes for highquality MNPs. ${ }^{9}$ Sun et al. reported the synthesis of monodisperse $\mathrm{Fe}_{3} \mathrm{O}_{4}$ nanoparticles with sizes varying from 3 to $20 \mathrm{~nm}$ in diameter, based on a simple organic phase process. ${ }^{11}$ A typical process involves the high-temperature decomposition $\left(>250^{\circ} \mathrm{C}\right)$ of an organic iron precursor, such

(8) Burda, C.; Chen, X.; Narayanan, R.;El-Sayed, M. A. Chem. Rev. 2005 , 105, 1025.

(9) Hyeon, T. Chem. Commun. 2003, 8, 927

(10) Tartaj, P.; Morales, M. P.; Veintemillas-Verdaguer, S.; GonzálesCarreño, T.; Serna, C. J. J. Phys. D: Appl. Phys. 2003, 36, R182.

(11) Sun, S.; Zeng, H. J. Am. Chem. Soc. 2002, 124, 8204. 
as iron(III) acetylacetonate, in the presence of surfactants, such as oleic acid. This method has been further adapted by other researchers to synthesize all types of magnetic nanoparticles containing different materials such as $\mathrm{Co}, \mathrm{Mn}, \mathrm{Ni}$, Pt, etc. ${ }^{9,12-15}$

The nanoparticles resulting from these procedures are stable in nonpolar solvents (such as hexane) and capped with nonpolar endgroups on their surface. The capping molecules (also called ligands) are typically long-chain alkanes with polar groups that bind to the nanoparticles' surface. Oleic acid is widely used in ferrite nanoparticle synthesis because it can form a dense protective monolayer, thereby producing highly uniform and monodisperse particles. ${ }^{9} \mathrm{Wu}$ et al. have shown that oleic acid is chemisorbed on the particle surface as a carboxylate with its nonpolar $\mathrm{CH}_{3}$ endgroup sticking out into solution. ${ }^{16}$ The nonpolar endgroups render these particles stable in nonpolar solvents because they allow the creation of a surface that is mutually unreactive and repulsive, which is commonly considered to be steric stabilization. Although the thermal decomposition method has the advantage of producing very monodisperse particles, it has the big disadvantage that the resulting nanoparticles are only soluble in nonpolar solvents. Hence, to make ferrite MNPs suitable for biological applications, the hydrophobic surfactant coating needs to be replaced by a hydrophilic, biocompatible, and functional coating that allows controlled interaction with biological species.

Ligand exchange is a well-known method for tuning the surface properties of nanoparticles. It involves adding an excess of ligand to the nanoparticle solution, which results in the displacement of the original ligand on the nanoparticles' surface. Especially, ligand-exchange reactions on noble metal nanoparticles, via the self-assembly of thiols, have been used for many years already. ${ }^{17,18}$ However, more recently, several groups have reported the use of ligand exchange to alter the surface properties of ferrite MNPs. Most ligands discussed in these reports contain a carboxylate $\left(\mathrm{COO}^{-}\right),{ }^{19,20}$ a phosphate $\left(\mathrm{PO}_{3}{ }^{2-}\right),{ }^{21,22}$ or an alcohol $(\mathrm{OH})^{23}$ endgroup to chemically adsorb to the nanoparticle surface and form a protective coating. However, the aqueous stability of these nanoparticles, including that in biological media, has not been established unambiguously. At the same time, it has to be

(12) Song, Q.; Zhang, Z. J. J. Am. Chem. Soc. 2004, 126, 6164.

(13) Sun, S.; Zeng, H.; Robinson, D. B.; Raoux, S.; Rice, P. M.; Wang, S. X.; Li, G. J. Am. Chem. Soc. 2004, 126, 273.

(14) Chen, M.; Liu, J. P.; Sun, S. J. Am. Chem. Soc. 2004, 126, 8394.

(15) Sun, S. Adv. Mater. 2006, 18, 393.

(16) Wu, N.; Fu, L.; Su, M.; Aslam, M.; Wong, K.C.; Dravid, V.P. Nano Lett. 2004, 4, 383.

(17) Ingram, R. S.; Hostetler, M. J.; Murray, R. W. J. Am. Chem. Soc. 1997, 119, 9175.

(18) Hostetler, M. J.; Green, S. J.; Stokes, J. J.; Murray, R. W. J. Am. Chem. Soc. 1996, 118, 4212.

(19) White, M. A.; Johnson, J. A.; Koberstein, J. T.; Turro, N. J. J. Am. Chem. Soc. 2006, 128, 11356.

(20) Huh, Y.-M.; Jun, Y.-w.; Song, H.-T.; Kim, S.; Choi, J.-s.; Lee, J.-H.; Yoon, S.; Kim, K.-S.; Shin, J.-S.; Suh, J.-S.; Cheon, J. J. Am. Chem. Soc. 2005, 127, 12387.

(21) Grancharov, S. G.; Zeng, H.; Sun, S.; Wang, S. X.; O’Brien, S. Murray, C. B.; Kirtley, J. R.; Held, G. A. J. Phys. Chem. B 2005, 109, 13030.

(22) Robinson, D. B.; Persson, H. H. J.; Zeng, H.; Li, G.; Pourmand, N.; Sun, S.; Wang, S. X. Langmuir 2005, 21, 3096.

(23) Hong, R.; Fischer, N. O.; Emrick, T. Rotello, V. M. Chem. Mater. 2005, 17, 4617. noted that the binding of these ligands is noncovalent, which means that they can be more easily desorbed from the surface, ${ }^{19}$ which strongly affects the long-term stability of the nanoparticles. Furthermore, these ligands have only been reported with a limited variety of endgroups, thereby restricting their versatility and applicability. To meet this demand of versatility, a more robust and general route for decorating ferrite MNPs with diverse functionalities has to be developed.

Recently, polymeric grafting is becoming increasingly popular as a way to tune the surface properties of nanoparticles. ${ }^{24,25,26}$ However, these methods often rely on several subsequent grafting steps, thereby making it a process that is more complicated and harder to control. Therefore, inspired by the effectiveness and simplicity of silane self-assembly on planar oxide substrates, ${ }^{27,28}$ our research group has conducted ligand exchange on hydrophobic ferrite MNPs using alkylsilanes. Recently, silanes have been increasingly reported as being important functionalization agents for ferrite MNPs. ${ }^{29,30}$ However, all of these reports have solely focused on the silanization of ferrite nanoparticles, made via water-based methods. ${ }^{31-33}$ We report here the first example of silanes to exchange the hydrophobic ligands on ferrite MNPs, synthesized via the thermal decomposition method. For the effective stabilization of nanoparticles, a very high density and stability of the coating is desirable..$^{22}$ Silanes can fulfill these high requirements, because they are known to form a densely packed film, which is covalently linked to the surface. ${ }^{27}$ At the same time, they exhibit the major advantage that they are commercially available bearing a huge variety of functional endgroups. Consequently, we could also address the effect of the endgroup on the waterdispersibility of ferrite MNPs. To the best of our knowledge, this is the first systematic report of silane ligand exchange on hydrophobic ferrite MNPs, representing a generic and versatile method for synthesizing highly stable, waterdispersible nanoparticles with a tunable ligand periphery.

\section{Experimental Section}

Materials. The Au substrates used as carriers in XPS and EDX measurements were prepared by depositing $2 \mathrm{~nm}$ Ti and $50 \mathrm{~nm}$ $\mathrm{Au}$ on a silicon wafer, using electron-beam evaporation. 3-Aminopropyltriethoxysilane (amino-silane), triethoxysilylbutyraldehyde (short aldehyde-silane), 3-isocyanatopropyltriethoxysilane (isocyanate-silane), 3-mercaptopropylthrimethoxysilane (thiol-silane), 11cyanoundecyltrimethoxysilane (cyano-silane), 3-acryloxypropyltrimethoxysilane (acrylate-silane), triethoxysilylundecanal (long aldehyde-silane), $n$-(trimethoxysilylpropyl)ethylene diamine triacetic acid (45\% in water) (carboxylic acid-silane), and 2-[methoxy-

(24) Lattuada, M.; Hatton, T.A. Langmuir 2007, 23, 2158

(25) Kohut, A.; Voronov, A.; Peukert, W. Langmuir 2007, 23, 504.

(26) Kohut, A.; Ranjan, S.; Voronov, A.; Peukert, W.; Tokarev, V.; Bednarska, O.; Gevus, O.; Voronov, S. Langmuir 2006, 22, 6498.

(27) Onclin, S.; Ravoo, B. J.; Reinhoudt, D. N. Angew. Chem., Int. Ed. 2005, 44, 6282.

(28) De Palma, R.; Laureyn, W.; Frederix, F.; Bonroy, K.; Pireaux, J.-J.; Borghs, G.; Maes, G. Langmuir 2007, 23, 443.

(29) Bruce, I. J.; Sen, T. Langmuir 2005, 21, 7029.

(30) Yamaura, M.; Camilo, R. L.; Sampaio, L. C.; Macêdo, M. A.; Nakamura, M.; Toma, H. E. J. Magn. Magn. Mater. 2004, 279, 210

(31) Koh, I.; Wang, X.; Varughese, B.; Isaacs, L.; Ehrman, S. H.; English, D. S. J. Phys. Chem. B 2006, 110, 1553.

(32) Pan, B.-F.; Gao, F.; Gu, H.-C. J. Colloid Interface Sci. 2005, 284, 1

(33) Zhang, Y.; Kohler, N.; Zhang, M. Biomaterials 2002, 23, 1553. 
(polyethyleneoxy)propyl]trimethoxysilane (poly[ethylene glycol]silane) were obtained from ABCR gmbh. Ethanol (Puranal) was purchased from Honeywell and oleylamine (97\%) was purchased from Acros Organics. Hexane (>98\%), benzylether (99\%), cobalt(II) acetylacetonate $(99.99 \%)$, iron(III) acetylacetonate $\left(\mathrm{Fe}(\mathrm{acac})_{3}\right.$; $99.9 \%$ ), oleic acid (90\%), and 1,2-hexadecanediol (90\%) were obtained from Sigma-Aldrich. Acetone (Cleanroom) was from Air Products.

Nanoparticle Synthesis. Monodisperse cobalt ferrite $\left(\mathrm{CoFe}_{2} \mathrm{O}_{4}\right)$ magnetic nanoparticles were prepared following a standard procedure reported by Sun et al. ${ }^{13}$ Briefly, $2 \mathrm{mmol} \mathrm{Fe}(\mathrm{acac})_{3}, 1 \mathrm{mmol}$ $\mathrm{Co}(\mathrm{acac})_{2}, 10 \mathrm{mmol}$ 1,2-hexadecanediol, $6 \mathrm{mmol}$ oleic acid, $6 \mathrm{mmol}$ oleylamine, and $20 \mathrm{~mL}$ of benzylether were mixed and magnetically stirred under a flow of $\mathrm{N}_{2}$. The mixture was slowly heated to 200 ${ }^{\circ} \mathrm{C}$ for $2 \mathrm{~h}$ and then, under a blanket of $\mathrm{N}_{2}$, heated to reflux $(\sim 300$ ${ }^{\circ} \mathrm{C}$ ) for $1 \mathrm{~h}$. The black-colored mixture was cooled to room temperature by removing the heat source. Under ambient conditions, ethanol $(\sim 50 \mathrm{~mL})$ was added to the mixture and a black material was precipitated. The black precipitate was washed three times (using a rare earth magnet) with ethanol to remove any left-over surfactants in solution. Finally, the MNPs were dispersed in hexane $(50 \mathrm{~mL})$ to obtain a black dispersion of $\mathrm{CoFe}_{2} \mathrm{O}_{4}$ nanoparticles at a concentration of $\sim 10 \mathrm{mg} / \mathrm{mL}$. The correct magnetic nanoparticles concentration was determined using thermal gravimetric analysis (TGA).

Surface Functionalization via Ligand Exchange. In a glass container under ambient conditions, $0.5 \%(\mathrm{v} / \mathrm{v})$ trialkoxysilane solution was added to a dispersion of hydrophobic $\mathrm{CoFe}_{2} \mathrm{O}_{4}$ nanoparticles in hexane $(6 \mathrm{mg}$ in $30 \mathrm{~mL})$ containing $0.01 \%(\mathrm{v} / \mathrm{v})$ acetic acid. The mixture was shaken for $72 \mathrm{~h}$, during which the particles precipitated. It has to be noted that the degree of precipitation was found to be strongly dependent on the type of silane applied. The black-brown precipitate was separated using a magnet. During the magnetic separation step, the particles were washed three times with hexane to remove all excess silanes. The product was finally redispersed in deionized water. No quantitative assessment of the yield of the ligand exchange reactions was performed. However, it was noted that for the exchange with $\mathrm{COOH}-, \mathrm{NH}_{2-}$ and PEG-silanes, a complete precipitation was observed after $72 \mathrm{~h}$. Finally, all precipitates could be redispersed in water, indicating an excellent yield of the reaction.

Characterization Methods. Transmission Electron Micrographs. TEM images were recorded on a $300 \mathrm{kV}$ Philips CM30 instrument equipped with a field emission gun electron source. A drop of suspension of the MNPs was placed onto a carbon-coated copper grid (Holey Carbon, 300 mesh $\mathrm{Cu}$ ) and left to dry at room temperature. The size distribution was determined on at least 50 particles visualized on the TEM images.

Thermal Gravimetric Analysis. TGA was performed on a TA instruments Q5000 IR under a $\mathrm{N}_{2}$ atmosphere. To determine the concentration of magnetic nanoparticles, we heated $100 \mu \mathrm{L}$ of MNPs to $80{ }^{\circ} \mathrm{C}$ at $10{ }^{\circ} \mathrm{C} / \mathrm{min}$ and kept it at $80{ }^{\circ} \mathrm{C}$ for $30 \mathrm{~min}$ to remove all solvent. Next the samples were heated to $1000^{\circ} \mathrm{C}$ at 20 ${ }^{\circ} \mathrm{C} / \mathrm{min}$ to determine the amount of organic coating on the nanoparticle surface.

Fourier Transform Infrared Spectroscopy. FTIR spectra of the MNPs were collected on a Bruker IFS66/v and samples were dried overnight at $50{ }^{\circ} \mathrm{C}$ in a vacuum prior to $\mathrm{KBr}$-pellet fabrication. Three hundred milligrams of $\mathrm{KBr}$ was thoroughly mixed and crushed with approximately $1 \mathrm{mg}$ of dried particles, and $200 \mathrm{mg}$ was used for pellet fabrication. For each FTIR spectrum, 2048 scans were recorded between 4000 and $500 \mathrm{~cm}^{-1}$ at a resolution of $1 \mathrm{~cm}^{-1}$.

$U V$-vis Spectroscopy. UV-vis spectroscopy was conducted on a Shimadzu UV-1601PC spectrophotometer. UV-vis absorbances of the MNPs dispersed in water were measured every 2 min for 14 $\mathrm{h}$ at a fixed wavelength of $1000 \mathrm{~nm}$.

Dynamic Light Scattering and Zeta Potential. DLS and zeta potential measurements were performed on a Brookhaven ZetaPALS with Bi-Mas particle sizing option. Zeta potentials were recorded for a solution of MNPs in water between $\mathrm{pH} 2$ and 12 . The $\mathrm{pH}$ of these solutions was adjusted using $10 \mathrm{mM} \mathrm{HCl}$ and 10 $\mathrm{mM} \mathrm{NaOH}$.

Superconducting Quantum Interference Device Magnetometry. SQUID (Quantum Design MPMS-XL) was used to determine the magnetic characteristics of the MNPs. Magnetization curves as a function of magnetic field were measured at $300 \mathrm{~K}$ for magnetic fields up to $20 \mathrm{kOe}$. The samples were prepared by adding $20 \mu \mathrm{L}$ of nanoparticles into a capsule filled with cotton.

$X$-ray Photoelectron Spectroscopy. XPS was performed on a Theta300 spectrometer (Thermo electron corporations) equipped with a monochromatized $\mathrm{Al} \mathrm{K \alpha}$ source. The binding energies were determined with respect to the $(\mathrm{CH})_{x}$ component in the $\mathrm{C} 1 \mathrm{~s}$ peak, which was set at $284.6 \mathrm{eV}$. XPS data fittings were performed using software developed at the FUNDP-LISE (University of Namur, Belgium), which is comprised of a simple routine using mixed Gaussian-Lorentzian curves and a Shirley background. A drop of a suspension of magnetic nanoparticles was placed onto a $\mathrm{Au}$ substrate (piranha-cleaned prior to use) and left to dry at room temperature. Piranha consists of a $1 / 3$ mixture of $\mathrm{H}_{2} \mathrm{O}_{2} / \mathrm{H}_{2} \mathrm{SO}_{4}$ (Caution! Piranha solution reacts violently with organic material). Au was used as a carrier substrate to avoid overlap of sample peaks with background peaks. The surface elemental concentrations were calculated without taking the Au peak into account.

Energy-Dispersive X-ray Analysis. EDX was conducted on JEOL JSM 55600LV scanning electron microscope operated at $20 \mathrm{kV}$. Sample preparation was performed as described above for XPS analysis.

\section{Results and Discussion}

Silane Ligand Exchange. Ferrites form an interesting class of magnetic materials because they contain a high magnetization as well as a high electrical resistance, two properties that are typically mutually exclusive. At sizes below approximately $20 \mathrm{~nm}$, all ferrites are superparamagnetic at room temperature, which makes them ideal candidates for many biological applications. We chose monodisperse $\mathrm{CoFe}_{2} \mathrm{O}_{4}$ nanoparticles as a model to investigate the silane ligand exchange on ferrite nanoparticles and to study their stability and water-dispersibility. $\mathrm{CoFe}_{2} \mathrm{O}_{4}$ has a high magnetic anisotropy compared to other ferrites, such as $\mathrm{Fe}_{2} \mathrm{O}_{3}, \mathrm{Fe}_{3} \mathrm{O}_{4}$ or $\mathrm{MnFe}_{2} \mathrm{O}_{4} \cdot{ }^{13}$ Our $\mathrm{CoFe}_{2} \mathrm{O}_{4}$ MNPs were synthesized according to Sun et al. ${ }^{13}$ As synthesized, these particles are coated with a hydrophobic ligand layer. Consequently, they can be dispersed only in nonpolar solvents. To render these MNPs dispersible in water, the hydrophobic ligands were exchanged by hydrophilic ligands. From a surface chemistry point of view, all ferrites act similarly as metal oxides, presenting a high number of reactive surface hydroxyl groups. ${ }^{34}$ In this paper, ligand exchange is performed by the covalent attachment of functional alkylsilanes to the nanoparticles' surface hydroxyl functions.

Silanes are bifunctional molecules with the general chemical formula $\mathrm{Y}-\left(\mathrm{CH}_{2}\right)_{n}-\mathrm{Si}-\mathrm{R}_{3}$, where $\mathrm{Y}$ represents the

(34) McCafferty, E.; Wightman, J. P. Surf. Interface Anal. 1998, 26, 549. 

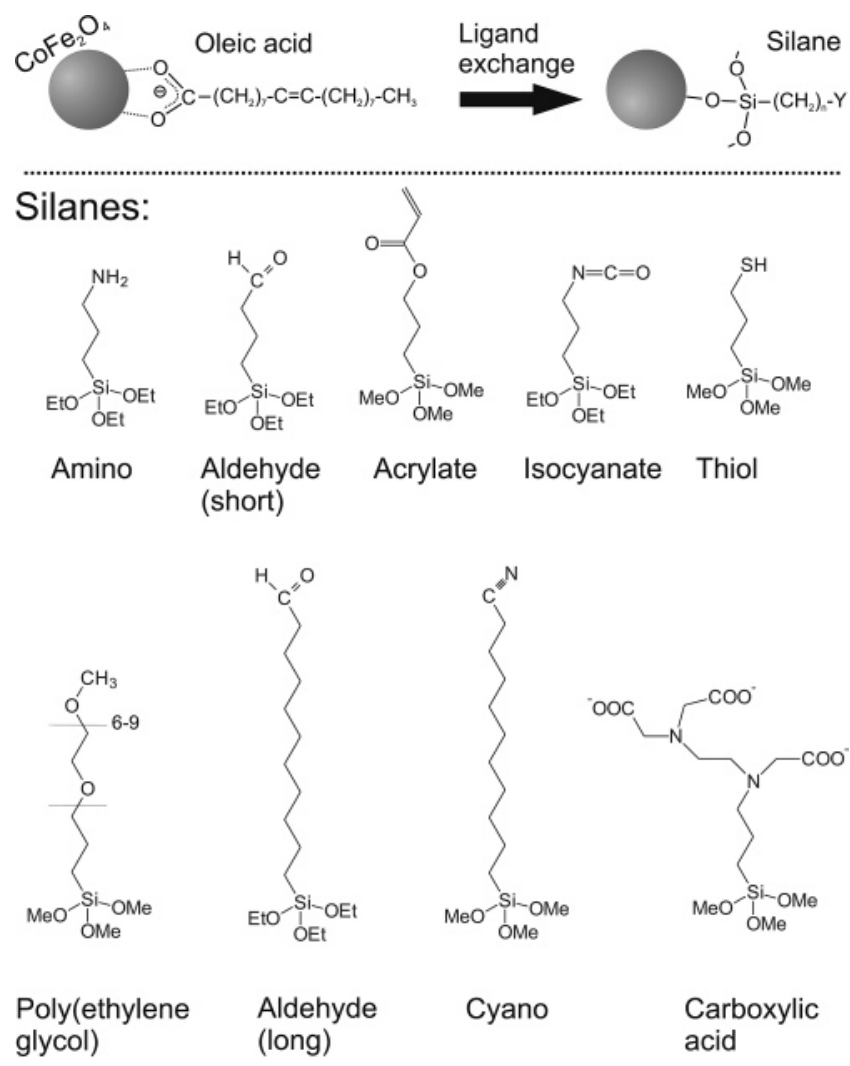

Figure 1. Exchange of the chemisorbed oleic acid ligands on the nanoparticle surface by silanes. Different silanes bearing a wide variety of endgroups were deposited on the nanoparticle surface in order to evaluate which groups can render these nanoparticles water-dispersible.

headgroup functionality, $\left(\mathrm{CH}_{2}\right)_{n}$ an alkane chain, and $\mathrm{Si}-$ $\mathrm{R}_{3}$ the anchor group by which the silane will be grafted to the metal oxide surface (with $\mathrm{R}$ being $\mathrm{Cl}$ or $\mathrm{OR}^{\prime}$ ). Because silanes are commercially available with a wide variety of $\mathrm{Y}$ functionalities, they form the ideal system to tune the surface functionality of our ferrite nanoparticles and to study their water-dispersibility. Figure 1 gives an overview of all silanes containing different endgroups and alkane chain lengths that were used to perform the ligand exchange. The characteristics of the deposited silane layer on the particles' surface strongly depend on reaction variables such as the type of solvent, the reaction time, the presence of a catalyst, the type of anchor group, and the silane concentration. ${ }^{27}$ The ways in which these parameters influence the surface modification process are generally known to be complicated and various. ${ }^{27}$ The situation is even more complicated in the case of nanoparticles in which particle aggregation and interparticle crosslinking can occur. ${ }^{29}$ Moreover, the homogeneity and extent of the silane ligand exchange may be crucial for the final performance of the ferrite MNPs and were therefore thoroughly characterized in this paper.

A first important observation regarding the silane ligand exchange procedure concerns the type of anchor groups. If chlorosilanes were applied, the nanoparticles were found to disintegrate immediately because of the liberation of $\mathrm{HCl}$, which is known to dissolve ferrite materials. ${ }^{35}$ Therefore, only (m)ethoxysilanes were further used in this study (Figure

(35) Vossen, J. L.; Kern, W. Thin Film Processes; Elsevier Science \& Technology Books: Amsterdam, 1978.
1). Trace amounts of acetic acid were also added to catalyze the reaction and as a reagent for the hydrolysis and condensation of the alkoxysilane groups. The rate of condensation is determined by the anchor group and by the solvent used. ${ }^{36}$ In our case, in which a nonpolar solvent (hexane) and an alkoxysilane are used, the condensation rates are known to be rather slow. ${ }^{29}$ Therefore, the reaction was performed for $72 \mathrm{~h}$ to ensure full exchange of the hydrophobic ligands and to promote a higher density of functional groups on the nanoparticles' surface. During the ligandexchange process more aggregation of the MNPs could gradually be observed, which changes the appearance of the nanoparticle-hexane dispersion from transparent to opaque. This aggregation in the nonpolar solvent was found to be characteristic for the successful exchange of the hydrophobic ligands with the hydrophilic silanes. When shorter reaction times (e.g., $24 \mathrm{~h}$ ) were applied, a different solvent was used (e.g., toluene), or lower silane concentrations were used (e.g., $0.1 \%$ ), less aggregation could be noticed, probably because of an incomplete exchange of the hydrophobic ligands with the silanes.

To demonstrate the successful silane ligand exchange onto ferrite MNPs, we inspected the nanoparticles using FTIR (Figure S1 in the Supporting Information). Table 1 gives an overview of the most important IR vibrations before and after modification via silane ligand exchange. The unmodified MNPs showed strong $\mathrm{CH}_{2}$ bands at 2922, 2852, and 1462 $\mathrm{cm}^{-1}$. These bands are known to be characteristic for the $\mathrm{CH}_{2}$ chains that are present in oleic acid. ${ }^{37}$ The presence of oleic acid was further confirmed by three alkene stretchings at 3062,3004 , and $1684 \mathrm{~cm}^{-1}$, two $\mathrm{CH}_{3}$ stretchings at 2955 and $2870 \mathrm{~cm}^{-1}$, and two carboxylate stretchings at 1543 and $1407 \mathrm{~cm}^{-1}$. These carboxylate stretchings confirm the observations made by other researchers ${ }^{16,38,39}$ that oleic acid is chemisorbed onto the nanoparticles' surface via its carboxylate group through a bidentate bond rather then a monodentate bond (Figure 1). The strong IR band at 585 $\mathrm{cm}^{-1}$ is characteristic of the $\mathrm{Fe}-\mathrm{O}$ vibrations related to the ferrite core. ${ }^{40}$ After ligand exchange, a broadening and shift of the $\mathrm{Fe}-\mathrm{O}$ band were observed, which is dedicated to the formation of $\mathrm{Fe}-\mathrm{O}-\mathrm{Si}$ bonds in the silane layer ${ }^{30}$ (see Figure $\mathrm{S} 1$ in the Supporting Information). Compared to the assynthesized oleic acid stabilized MNPs, several new bands are observed in the spectra for silane-modified MNPs (see Figure S1 in the Supporting Information). The most striking difference is the appearance of bands between 1000 and 1150 $\mathrm{cm}^{-1}$. These bands are characteristic of silane layers and originate from $\mathrm{Si}-\mathrm{O}-\mathrm{Si}$ vibrations. ${ }^{41}$ The alkane chain present in all silanes results in the appearance of typical bands at $2922-2931$ and $2852-2856 \mathrm{~cm}^{-1}$, attributed to asymmetric and symmetric $\mathrm{CH}_{2}$ stretchings (Table 1), respectively. The position of these $\mathrm{CH}_{2}$ stretching vibrations is known to give more information about the crystalline packing of the

(36) Fadeev, A. Y.; McCarthy, T. J. Langmuir 2000, 16, 7268.

(37) Lee, S.-Y.; Harris, M. T. J. J. Colloid Interface Sci. 2006, 293, 401.

(38) Willis, A. L.; Turro, N. J.; O'Brien, S. Chem. Mater. 2005, 17, 5970.

(39) Zhang, L.; He, R.; Gu, H. C. Appl. Surf. Sci. 2006, 253, 2611.

(40) Waldron, R. V. Phys. Rev. 1955, 99, 1727.

(41) Launer, P.J. Silicone Compounds Register and Review; Petrarch Systems: Levittown, PA, 1987. 
Table 1. Characteristic FTIR Vibrations for Oleic-Acid- and Silane-Modified Magnetic Nanoparticles

\begin{tabular}{|c|c|c|c|}
\hline $\begin{array}{l}\mathrm{CoFe}_{2} \mathrm{O}_{4} \\
\text { modification }\end{array}$ & $\begin{array}{l}v_{\mathrm{a}} \mathrm{CH}_{2} \\
\left(\mathrm{~cm}^{-1}\right)\end{array}$ & $\begin{array}{l}v_{\mathrm{s}} \mathrm{CH}_{2} \\
\left(\mathrm{~cm}^{-1}\right)\end{array}$ & characteristic vibrations ${ }^{a}\left(\mathrm{~cm}^{-1}\right)$ \\
\hline oleic acid & 2922 & 2852 & $\begin{array}{l}3100-3600(v \mathrm{OH}), 3062\left(v_{\mathrm{a}} \mathrm{CH}=\right), 3004\left(v_{\mathrm{S}} \mathrm{CH}=\right), 2955\left(v_{\mathrm{a}} \mathrm{CH}_{3}\right), 2870\left(v_{\mathrm{s}} \mathrm{CH}_{3}\right), 1684(v \\
\mathrm{C}=\mathrm{C}), 1543\left(v_{\mathrm{a}} \mathrm{COO}^{-}\right), 1462(\mathrm{sh})\left(\delta \mathrm{CH}_{2}\right), 1407\left(v_{\mathrm{s}} \mathrm{COO}^{-} \text {and } \delta \mathrm{CH}_{2}-\mathrm{COO}^{-}\right), 585(v \mathrm{Fe}-\mathrm{O})\end{array}$ \\
\hline cyano & 2923 & 2852 & $\begin{array}{l}3100-3600(v \mathrm{OH}), 2240(v \mathrm{C} \equiv \mathrm{N}), 1631\left(\delta \mathrm{H}_{2} \mathrm{O}\right), 1459\left(\delta \mathrm{CH}_{2}\right), 1425\left(\delta \mathrm{CH}_{2}-\mathrm{C} \equiv \mathrm{N}\right), 1257 \\
(v \mathrm{Si}-\mathrm{C}), 1116 \& 1060 \& 1016(v \mathrm{Si}-\mathrm{O}-\mathrm{R}), 619 \& 594(v \mathrm{Fe}-\mathrm{O})\end{array}$ \\
\hline isocyanate & 2926 & 2854 & $\begin{array}{l}3100-3600(v \mathrm{OH}), 2954(\mathrm{sh})\left(v_{\mathrm{a}} \mathrm{CH}_{3}\right), 2253(v \mathrm{~N}=\mathrm{C}=\mathrm{O}), 1637(v \mathrm{C}=\mathrm{O}), 1556(v \mathrm{C}=\mathrm{N}) \\
1438\left(\delta \mathrm{CH}_{2}\right), 1409(\mathrm{sh})\left(\delta \mathrm{CH}_{2}-\mathrm{N}=\mathrm{C}=\mathrm{O}\right), 1259(v \mathrm{Si}-\mathrm{C}), 1195(v \mathrm{C}-\mathrm{N}), 1103 \& 1078 \& \\
1039(v \mathrm{Si}-\mathrm{O}-\mathrm{R}), 620 \& 599(v \mathrm{Fe}-\mathrm{O})\end{array}$ \\
\hline acrylate & 2926 & 2854 & $\begin{array}{l}3100-3600(v \mathrm{OH}), 2952(\mathrm{sh})\left(v_{\mathrm{a}} \mathrm{CH}_{3}\right), 1722(v \mathrm{C}=\mathrm{O}), 1631(v \mathrm{C}=\mathrm{C}), 1457\left(\delta \mathrm{CH}_{2}\right), 1407 \\
\left(\delta \mathrm{CH}_{2}-\mathrm{OCO}-\mathrm{C}=\mathrm{C}\right), 1268(\mathrm{sh})(v \mathrm{Si}-\mathrm{C}), 1197(v \mathrm{C}-\mathrm{O}), 1116 \& 1049(v \mathrm{Si}-\mathrm{O}-\mathrm{R}), 979 \\
\left(\tau \mathrm{CH}_{2}=\right), 590(v \mathrm{Fe}-\mathrm{O})\end{array}$ \\
\hline thiol & 2925 & 2854 & $\begin{array}{l}3100-3600(v \mathrm{OH}), 2954(\mathrm{sh})\left(v_{\mathrm{a}} \mathrm{CH}_{3}\right), 1631\left(\delta \mathrm{H}_{2} \mathrm{O}\right), 1450\left(\delta \mathrm{CH}_{2}\right), 1238(v \mathrm{Si}-\mathrm{C}), 1108 \& \\
1035(v \mathrm{Si}-\mathrm{O}-\mathrm{R}), 619 \& 597(v \mathrm{Fe}-\mathrm{O})\end{array}$ \\
\hline $\begin{array}{l}\text { aldehyde } \\
\text { (short alkane) }\end{array}$ & 2931 & 2856 & $\begin{array}{l}3100-3600(v \mathrm{OH}), 2972\left(v_{\mathrm{a}} \mathrm{CH}_{2}-\mathrm{CHO}\right), 2881\left(v_{\mathrm{s}} \mathrm{CH}_{2}-\mathrm{CHO}\right), 2812(v \mathrm{CHO}), 2717(\delta \mathrm{CHO}), \\
1722(v \mathrm{CH}=\mathrm{O}), 1457\left(\delta \mathrm{CH}_{2}\right), 1401\left(\delta \mathrm{CH}_{2}-\mathrm{CHO}\right), 1380(\mathrm{sh})(\delta \mathrm{CHO}), 1222(v \mathrm{Si}-\mathrm{C}), \\
1103 \& 1035(v \mathrm{Si}-\mathrm{O}-\mathrm{R}), 590(v \mathrm{Fe}-\mathrm{O})\end{array}$ \\
\hline $\begin{array}{l}\text { aldehyde } \\
\text { (long alkane) }\end{array}$ & 2923 & 2852 & $\begin{array}{l}3100-3600(v \mathrm{OH}), 2974(\mathrm{sh})\left(v_{\mathrm{a}} \mathrm{CH}_{2}-\mathrm{CHO}\right), 1709(v \mathrm{CH}=\mathrm{O}), 1455\left(\delta \mathrm{CH}_{2}\right), 1435 \\
\left(\delta \mathrm{CH}_{2}-\mathrm{CHO}\right), 1408(\delta \mathrm{CHO}), 1255(v \mathrm{Si}-\mathrm{C}), 1115 \& 1072(v \mathrm{Si}-\mathrm{O}-\mathrm{R}), 623 \& 592(v \mathrm{Fe}-\mathrm{O})\end{array}$ \\
\hline $\begin{array}{l}\text { poly(ethylene } \\
\text { glycol) }\end{array}$ & 2924 & $2853(\mathrm{sh})$ & $\begin{array}{l}3100-3600(v \mathrm{OH}), 2866\left(v_{\mathrm{s}} \mathrm{EG} \mathrm{CH}_{2}\right), 2820(\mathrm{sh})\left(v_{\mathrm{s}} \mathrm{CH}_{3}\right), 2729(\mathrm{sh})(\mathrm{comb} .), 1643\left(\delta \mathrm{H}_{2} \mathrm{O}\right), \\
1452\left(\delta \mathrm{CH}_{2}\right), 1349\left(\omega_{\text {gauche }} \mathrm{EG} \mathrm{CH}_{2}\right), 1319(\mathrm{sh})\left(\omega_{\text {trans }} \mathrm{EG} \mathrm{CH}_{2}\right), 1294\left(\tau \mathrm{EG} \mathrm{CH} \mathrm{CH}_{2}\right), 1248 \\
\left(\tau \mathrm{EG} \mathrm{CH}_{2} \& v \mathrm{Si}-\mathrm{C}\right), 1196\left(\rho \mathrm{OCH}_{3}\right), 1107(v \mathrm{C}-\mathrm{O}-\mathrm{C}), 1047(v \mathrm{C}-\mathrm{O}-\mathrm{C}), 1160-1000 \\
(v \mathrm{Si}-\mathrm{O}-\mathrm{R}), 947\left(\rho \mathrm{EG} \mathrm{CH}_{2}\right), 624 \& 596(v \mathrm{Fe}-\mathrm{O})\end{array}$ \\
\hline amino & 2924 & 2853 & $\begin{array}{l}3100\left(v \mathrm{OH} \& v \mathrm{NH}_{2}\right), 2954\left(v_{\mathrm{S}} \mathrm{CH}_{3}\right), 1633 \& 1560\left(\delta \mathrm{NH}_{3}{ }^{+}\right), 1463\left(\delta \mathrm{CH}_{2}\right), 1226(v \mathrm{Si}-\mathrm{C}) \\
1186(v \mathrm{C}-\mathrm{N}), 1186 \& 1118 \& 1029(v \mathrm{Si}-\mathrm{O}-\mathrm{R}), 777 \& 688\left(\omega \mathrm{NH}_{2}\right), 617 \& 595(v \mathrm{Fe}-\mathrm{O})\end{array}$ \\
\hline $\begin{array}{l}\text { carboxylic } \\
\text { acid }\end{array}$ & 2924 & 2853 & $\begin{array}{l}3100-3600(v \mathrm{OH}), 2954\left(v_{\mathrm{a}} \mathrm{CH}_{3}\right), 1625 \& 1587\left(v_{\mathrm{a}} \mathrm{COO}^{-}\right), 1455\left(\delta \mathrm{CH}_{2}\right), 1401 \\
\left(\delta \mathrm{CH}_{2}-\mathrm{COO}^{-} \& v_{\mathrm{s}} \mathrm{COO}^{-}\right), 1257(v \mathrm{Si}-\mathrm{C}), 1197(v \mathrm{C}-\mathrm{N}), 1116 \& 1089(v \mathrm{Si}-\mathrm{O}-\mathrm{R}), 619 \& \\
592(v \mathrm{Fe}-\mathrm{O})\end{array}$ \\
\hline
\end{tabular}

${ }^{a} \mathrm{sh}=$ shoulder; $\mathrm{EG}=$ ethylene glycol; R $=\mathrm{H}, \mathrm{C}, \mathrm{Si} ; v_{\mathrm{a}}=$ asymmetric stretching; $v_{\mathrm{s}}=$ symmetric stretching; $\delta=$ scissoring; $\omega=$ wagging; $\tau=$ twisting; $\rho=$ rocking; comb. $=$ combination vibration.

alkane chains in the silane layer. ${ }^{42}$ The measured values can be compared to IR data for highly ordered and crystalline $n$-decanethiols on planar $\mathrm{Au},{ }^{43}$ which show absorptions at 2918 and $2851 \mathrm{~cm}^{-1}$, respectively. The observed values (2923-2931 $\left.\mathrm{cm}^{-1}\right)$ implicate that the silane layers deposited on the ferrite MNPs do not exhibit high crystallinity. This low degree of crystallinity is most probably attributed to the presence of polymerization in the silane layer and the formation of silane multilayers. To the best of our knowledge, no earlier reports elucidated on the crystallinity of silanes on ferrite MNPs, thereby limiting further comparison. The degree of crystallinity observed for the oleic acid coating (Table 1) corresponds well with values reported in literature. ${ }^{16,37}$ For all silanes, a full exchange of the oleic acid coating was observed, as confirmed by the complete disappearance of the three alkene stretchings at 3062, 3004, and $1684 \mathrm{~cm}^{-1}$. The disappearance of the carboxylate stretchings at 1543 and $1407 \mathrm{~cm}^{-1}$ after ligand exchange could not be clearly observed as they are overshadowed by the appearance of new characteristic silane peaks (see Figure S1 in the Supporting Information). Notable, is the appearance of a small band at $\sim 2954 \mathrm{~cm}^{-1}$ in the case of isocyanate-, acrylate-, thiol-, amino-, and carboxylic acid-silanes. This band is dedicated to the symmetric $\mathrm{CH}_{3}$ stretching of the alkoxy anchor group and gives proof of an incomplete hydrolysis of the silane molecules during ligand exchange. Furthermore, the presence of the characteristic endgroups in the different silane layers was confirmed by the appearance of their typical vibrations (Table 1). We will only expand

(42) Ulman, A. An Introduction to Ultrathin Organic Films: from Langmuir-Blodgett to Self-Assembly; Academic Press: New York, 1991.

(43) Porter, M. D.; Gright, T. D.; Allara, D. L.; and Chidsey, C. D. J. Am. Chem. Soc. 1987, 109, 3559. on the vibrations observed for $\mathrm{NH}_{2-}, \mathrm{COOH}-$, and PEGsilanes, because these are important in the following of this study. The presence of PEG is confirmed by its characteristic ethylene glycol vibrations (Table 1). The broadening of the bands in the $2800-3000 \mathrm{~cm}^{-1}$ region (see Figure S1 in the Supporting Information) is the result of strong overlapping of the $\mathrm{CH}_{2}$ stretchings (asymmetric and symmetric) in the PEG-tail and in the alkane chain. The asymmetric and symmetric $\mathrm{CH}_{2}$ stretchings were found at 2924 and 2853 $\mathrm{cm}^{-1}$, respectively. The bands at 1452, 1349, 1319, $1294 \&$ $1248,1107 \& 1047$, and $947 \mathrm{~cm}^{-1}$ correspond well with the $\mathrm{CH}_{2}-\mathrm{O}-\mathrm{CH}_{2}$ scissoring, wagging (gauche), wagging (trans), twisting, stretching, and rocking modes, respectively. PEG is known to exhibit different conformations such as amorphous, helical crystalline, and all-trans crystalline, dependent on its chain length and density. ${ }^{44}$ On the basis of a comparison with literature data, we can conclude that the PEG functions in the PEG-silane layer are mainly present in the amorphous phase. ${ }^{45}$ The amino-silane shows two $\mathrm{N}-\mathrm{H}$ bendings at 1633 and $1560 \mathrm{~cm}^{-1}$, characteristic of the presence of $\mathrm{NH}_{3}{ }^{+}$groups. The carboxylic acid-silane, on the other hand, is mainly present in its carboxylate form $\left(\mathrm{COO}^{-}\right)$, as shown by the two vibrations at 1587 and $1401 \mathrm{~cm}^{-1}$, assigned to the asymmetric and symmetric $\mathrm{COO}^{-}$stretchings, respectively.

Although FTIR unambiguously confirms the successful silane ligand exchange, XPS measurements were also performed to get more quantitative data on the structure of the silane layers. An example of two survey spectra, before and after silane ligand exchange, is presented in Figure S2

(44) Zwahlen, M.; Herrwerth, S.; Eck, W.; Grunze, M.; Hähner, G. Langmuir 2003, 19, 9305

(45) Harder, P.; Grunze, M.; Dahint, R.; Whitesides, G. M.; Laibinis, P. E. J. Phys. Chem. B 1998, 102, 426. 


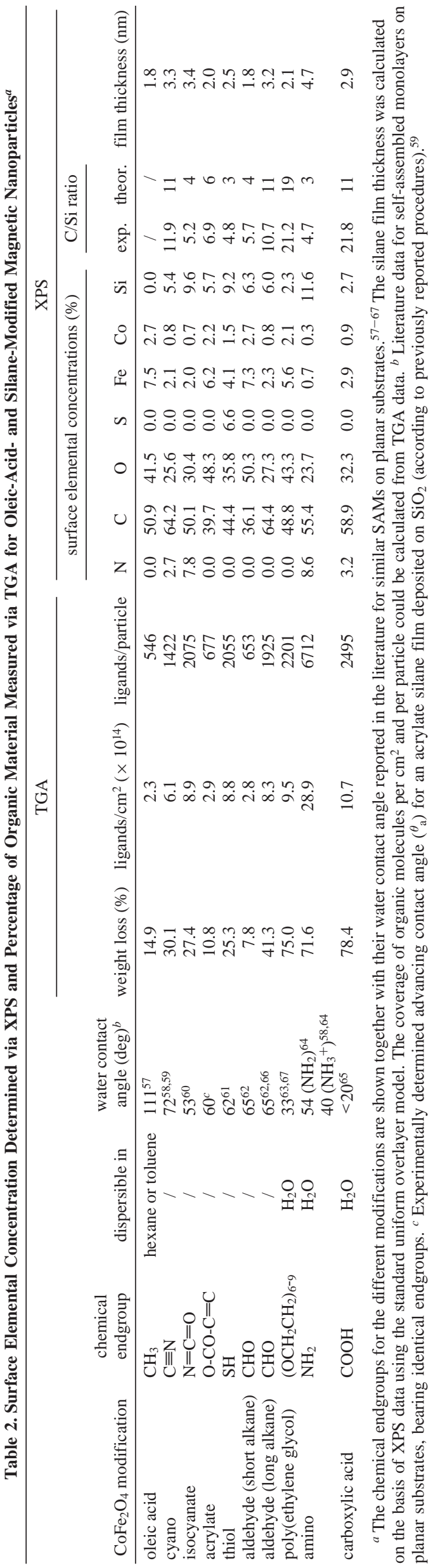

(see the Supporting Information), whereas Table 2 shows the surface elemental concentrations calculated from the survey spectra. After silane ligand exchange, the appearance of characteristic atoms such as sulfur and nitrogen could be observed (Table 2). For all silanes, the total amount of $\mathrm{Si}$ was found to increase drastically, whereas the $\mathrm{Fe}$ and $\mathrm{Co}$ concentration were found to decrease. The increase in Si can be explained by the deposition of a Si-rich silane layer, whereas the decrease in $\mathrm{Fe}$ and $\mathrm{Co}$ is dedicated to the attenuation of the $\mathrm{Fe} 2 \mathrm{p}$ and $\mathrm{Co} 2 \mathrm{p}$ photo electrons through the silane layer. From the attenuation of the Fe2p intensity, we could calculate the average thickness using the standard uniform overlayer model ${ }^{46}$ (Table 2)

$$
t=-\lambda_{\mathrm{Fe}} \sin \theta \ln \left(I_{\mathrm{Fe}} / I_{\mathrm{Fe}}{ }^{0}\right) \text { in } \AA
$$

where $t$ is the thickness of the silane film, $\lambda_{\mathrm{Fe}}$ is the escape depth for $\mathrm{Fe} 2 \mathrm{p}$ photo electrons through a carbon film (15 $\AA), \theta$ is the XPS collecting angle $\left(55^{\circ}\right), I^{0} \mathrm{Fe}$ is the intensity of the $\mathrm{Fe} 2 \mathrm{p}$ peak before ligand exchange, and $I_{\mathrm{Fe}}$ is the intensity of the Fe2p peak after ligand exchange. Apart from the amino-silane $(4.7 \mathrm{~nm})$, all thicknesses were found to be between 1.8 and $3.4 \mathrm{~nm}$. Dependent on their alkane chain length, monolayers of functional alkylsilanes on planar substrates are reported to be between 0.5 and $2 \mathrm{~nm} .{ }^{47}$ As compared to these values, our silanes did probably form slightly polymerized multilayers. This was especially the case for the amino-silane, for which a higher $\mathrm{Si}$ concentration and a thicker layer were observed (Table 2). Nevertheless, all silane coatings after ligand exchange stayed confined to a nanometer-thin molecular layer. In addition, the experimental $\mathrm{C} / \mathrm{Si}$ ratio is generally close to the theoretically predicted values for completely hydrolyzed silane films (Table 2). The good agreement between these data suggests the full exchange of the initial oleic acid ligands to form a contamination free and densely packed silane layer. ${ }^{48}$ However, in the case of isocyanate-, acrylate-, thiol-, short aldehyde-, amino-, and carboxylic acid-silanes, a higher $\mathrm{C} / \mathrm{Si}$ ratio was calculated. This can be assigned to the incomplete hydrolysis of the alkoxy anchor groups, which supports the previous findings from FTIR (Table 1). The as-synthesized MNPs, on the other hand, exhibited a $1.8 \mathrm{~nm}$ coating, which is in good accordance with a monolayer of oleic acid.

To further examine the chemical structure after silane ligand exchange, we deconvoluted the high-resolution XPS spectra of C1s (Figure 2) and O1s (see Figure S3 in the Supporting Information). For the oleic-acid-stabilized MNPs, the main peak at $284.6 \mathrm{eV}$ is assigned to the carbons in the alkane chain, whereas the small peak at $288.5 \mathrm{eV}$ is typical for a carboxylate carbon. ${ }^{38,39}$ These data support the findings from FTIR that oleic acid is chemisorbed onto the nanoparticles' surface through a bidentate bound carboxylate, which is in agreement with previous literature reports on oleic-acidstabilized MNPs. ${ }^{16,38,39}$ After silane ligand exchange, a $\mathrm{CH}_{x}$

(46) Petrovykh, D. Y.; Kimura-Suda, H.; Tarlov, M. J.; Whitman, L. J. Langmuir 2004, 20, 429.

(47) Wasserman, S. R.; Tao, Y.-T.; Whitesides, G. M. Langmuir 1989, 5, 1074.

(48) Cossement, D.; Pierard, C.; Delhalle, J.; Pireaux, J. J.; Hevesi, L.; Mekhalif, M. Surf. Interface, Anal. 2001, 31, 18. 

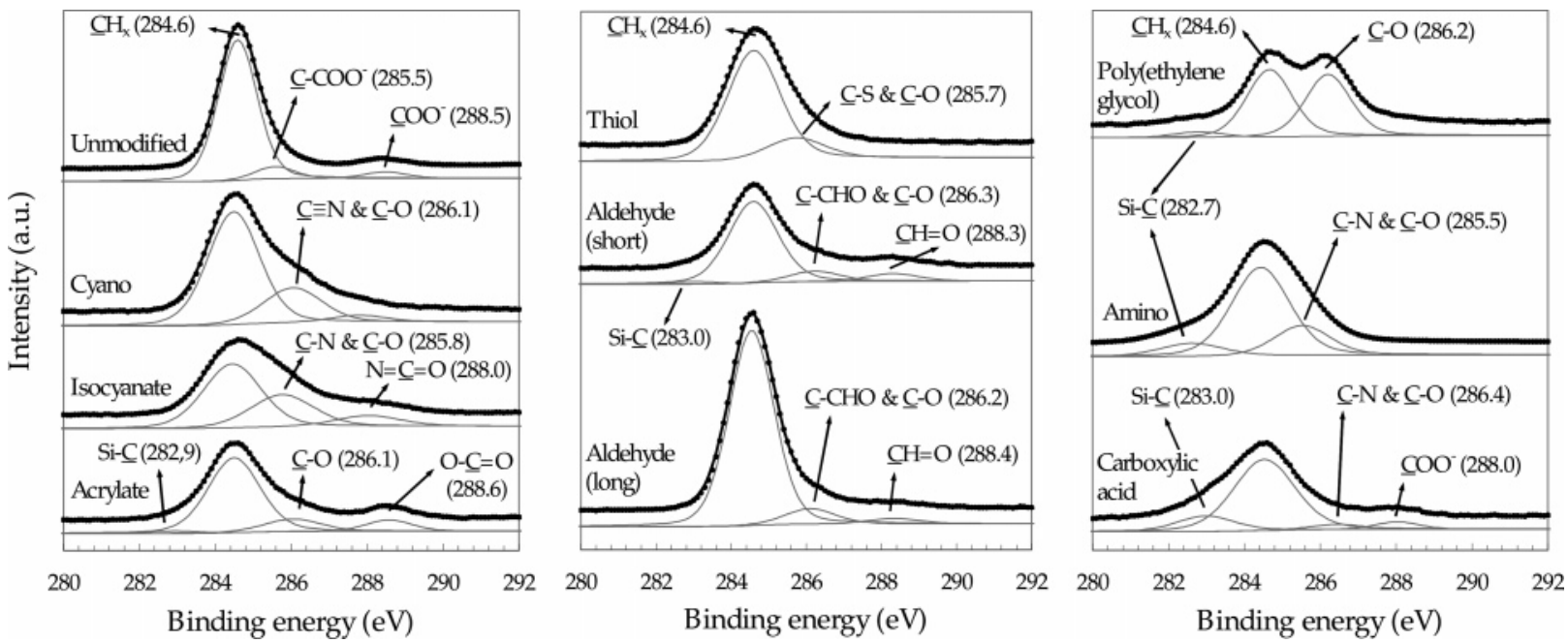

Figure 2. Deconvoluted high-resolution spectra of the $\mathrm{C} 1 \mathrm{~s}$ subregion for unmodified (oleic acid) and silane-modified magnetic nanoparticles. The different endgroups of the applied silanes are indicated in the spectrum. The measured spectra are represented by dots, the simulated individual peaks by light gray lines, and the overall simulated spectrum by a black line. For clarity reasons, an offset has been added to the simulated curves compared to the measured curves.

peak could be observed at $284.6 \mathrm{eV}$, assigned to the alkane chain in the silane layer. Especially in the case of the longalkane-chain silanes (i.e., cyano and aldehyde), this peak was found to be very distinct (Figure 2), and consequently, a higher overall carbon concentration could be noticed (Table 2 ). For some silanes, the $\mathrm{Si}-\mathrm{C}$ bond could also be observed at $\sim 283 \mathrm{eV}$. The presence of the characteristic endgroups in the different silane layers was also confirmed by additional deconvoluted peaks in the C1s subregion (Figure 2). For example, the carboxylic acid-silane presents a peak at 288.0 $\mathrm{eV}$, originating from a carboxylate carbon, ${ }^{38}$ which supports the previous FTIR findings (Table 1) that this silane is present in its basic $\mathrm{COO}^{-}$form. Amino- and PEG-functions in the silanes could be identified by their characteristic peaks in the deconvoluted $\mathrm{C} 1 \mathrm{~s}$ subregion at 285.5 and $286.2 \mathrm{eV}$, respectively.

Apart from the presence of Si in the XPS spectrum, the successful silane ligand exchange also results in the appearance of two pronounced peaks in the O1s spectrum (see Figure $\mathrm{S} 3$ in the Supporting Information). All silane-modified MNPs show peaks at $\sim 531.5$ and $\sim 532.5 \mathrm{eV}$. These peaks are located at approximately $+2 \mathrm{eV}$ with respect to the principal $\mathrm{Fe}-\mathrm{O}$ peak $(\sim 530 \mathrm{eV})$ and can be mainly assigned to $\mathrm{Fe}-\mathrm{O}-\mathrm{Si}$ and $\mathrm{Si}-\mathrm{O}$ bonds, respectively. ${ }^{49}$ Furthermore, the XPS spectra of S2p, N1s, Si2p, and Fe2p were recorded (see Figure S4 in Supporting Information). The appearance of sulfur $(6.6 \%)$ could be observed when thiol-silane was deposited on the nanoparticles' surface (Table 1). The presence of thiol endgroups in this silane is also confirmed by two peaks at 163.5 and $164.7 \mathrm{eV}$, dedicated to $\mathrm{S} 2 \mathrm{p}_{1 / 2}$ and $\mathrm{S} 2 \mathrm{p}_{3 / 2}$, respectively, in the deconvoluted $\mathrm{S} 2 \mathrm{p}$ subregion. Nitrogen, on the other hand, could be observed only for cyano-, isocyanate-, amino-, and carboxylic-acid-modified MNPs (Table 2) and presents a peak at $\sim 399.5 \mathrm{eV}$. These findings were in good accordance with the chemical structure of the silanes, as described in Figure 1. After silane ligand exchange, the Si2p subregion presents a single peak at 103.0

(49) Turner, M. R.; Duguet, E.; Labrugère, C. Surf. Interface Anal. 1997, 25, 917.
$\mathrm{eV}$, typical for oxidized Si species in silane layers ${ }^{28,48}$ (Table 2). In this region, the Fe3s peak could also be identified at $98.5 \mathrm{eV}$.

Apart from studying the chemical structure of the deposited silane layer, XPS can also be used to study the ferrite composition. The $\mathrm{Fe} 2 \mathrm{p}$ doublet with binding energies of 712.0 and $725.5 \mathrm{eV}$ implies the presence of $\mathrm{Fe}-\mathrm{O}$ bonds, typical for ferrites. All $\mathrm{Fe} 2 \mathrm{p}$ spectra, before and after silane ligand exchange, were found to be identical. The composition of the ferrite MNPs could be determined via the Fe/Co ratio $(\sim 2.8)$ and was found to remain identical after silane ligand exchange (Table 2). On the basis of these $\mathrm{Fe} / \mathrm{Co}$ ratios, we proposed a $\mathrm{Co}_{0.8} \mathrm{Fe}_{2.2} \mathrm{O}_{4}$ composition. These observations were further supported by EDX measurements (see Figure S5 in the Supporting Information) and are in good agreement with the ratio of initial metal precursors $(\mathrm{Fe} / \mathrm{Co}=2)$. The unaltered $\mathrm{Fe} 2 \mathrm{p}$ spectra and $\mathrm{Fe} / \mathrm{Co}$ ratios after silane modification give clear proof that the silane ligand exchange did not impose any compositional changes to the ferrite MNPs.

TGA provides additional quantitative evidence on the structure of the nanoparticles' coating before and after silane ligand exchange. In this experiment, the MNPs are heated to $1000{ }^{\circ} \mathrm{C}$ under flowing $\mathrm{N}_{2}$ and changes in mass due to loss of organic material are recorded. Although it is an extremely valuable technique for surface characterization of nanoparticles, it is not commonly applied in literature for ferrite MNPs. The information one can retrieve from TGA measurements is bipartite. First of all, TGA allows us to determine the bonding strength of the ligand to the nanoparticles' surface and its thermal stability. Typically, ligands that are bound more strongly desorb at higher temperatures..$^{22}$ The as-synthesized oleic-acid-stabilized MNPs show a strong primary mass loss at $\sim 280{ }^{\circ} \mathrm{C}$ followed by a second mass loss peak at higher temperatures $\left(\sim 400{ }^{\circ} \mathrm{C}\right.$; data not shown). This desorption pattern is in good agreement with patterns reported in the literature for oleic acid ligands ${ }^{39,50}$ and can

(50) Sahoo, Y.; Pizem, H.; Fried, T.; Golodnitsky, D.; Burstein, L.; Sukenik, C. N.; Markovich G. Langmuir 2001, 17, 7907. 
be explained by a bilayer structure of these ligands on the particle surface. After silane ligand exchange, an increase in desorption temperatures could be observed. Depending on the type of silane, primary mass loss occurred between 360 and $490{ }^{\circ} \mathrm{C}$, sometimes followed by a second mass loss between 500 and $700{ }^{\circ} \mathrm{C}$ (data not shown). This strong increase in desorption temperature compared to oleic acid is indicative of an increased bonding strength to the nanoparticles' surface and can be understood by the more covalent nature of the $\mathrm{Fe}-\mathrm{O}-\mathrm{Si}$ linkage. Compared to the commonly used carboxylate ligands, ${ }^{50}$ silanes probably have the major advantage that they cannot be easily removed or replaced from the nanoparticles' surface, thereby imposing an enhanced long-term stability to the MNPs.

Second, TGA can be used to quantify the coverage of ligand molecules surrounding each nanoparticle. Table 2 summarizes the weight loss and the ligand coverage, which could be calculated using the following formula

$$
N=\frac{\omega N_{\mathrm{A}} \rho \frac{4}{3} \pi R^{3} \times 10^{-23}}{M M}
$$

where $N$ is the number of ligands on each particle, $R$ is the mean radius of the cobalt ferrite nanoparticles $(4.3 \mathrm{~nm}$ based on TEM results), $\rho$ is the density of the nanoparticles (5.15 $\left.\mathrm{g} / \mathrm{cm}^{3}\right), N_{\mathrm{A}}$ is Avogadro's number, $M M$ is the molar mass of the ligand molecules $(\mathrm{g} / \mathrm{mol})$ and $\omega$ is the mass loss in percent (\%). From this formula, one can also easily calculate the number of molecules per square centimeter (Table 2). The ligand coverage observed for oleic-acid-stabilized MNPs is in good agreement with values reported in literature ${ }^{39}$ and proves the presence of a particle surface densely covered with a mono- or bilayer of oleic acid ligands. However, after silane ligand exchange, a general increase in coverage is observed. For silane layers on planar $\mathrm{SiO}_{2}$ and thiol selfassembled monolayers on planar $\mathrm{Au}$, typical coverages around $2-4 \times 10^{14}$ molecules $/ \mathrm{cm}^{2}$ are reported..$^{51}$ The rather high surface coverages observed after silane modification (Table 2) indicate the presence of a dense silane layer and could most probably be attributed to the formation of a polymerized silane multilayer and/or to the occupancy of alternative binding sites (edges, corners, and curvatures), typical for nanosized objects. Similar increases in surface coverage were experimentally reported ${ }^{52}$ and theoretically modeled for thiols on Au nanocrystals. ${ }^{53}$ Noteworthy are the high surface coverage for $\mathrm{NH}_{2^{-}}, \mathrm{COOH}-$, and PEG-silanes. Finally, the surface coverages calculated using TGA were found to correlate well with the film thicknesses determined via XPS.

Influence of Silane Ligand Exchange on the Nanoparticles' Water-Dispersibility. In the previous section, we have indicated that silane self-assembly can be successfully applied to exchange the original hydrophobic ligand from the

(51) Killampalli, A. S.; Ma, P. F.; Engstrom, J. R. J. Am. Chem. Soc. 2005, 127,6300 .

(52) Love, J. C.; Estroff, L. A.; Kriebel, J. K.; Nuzzo, R. G.; Whitesides, G. M. Chem. Rev. 2005, 105, 1103.

(53) Hostetler, M. J.; Stokes, J. J.; Murray, R. W. Curr. Opin. Colloid Interface Sci. 1997, 2, 42.

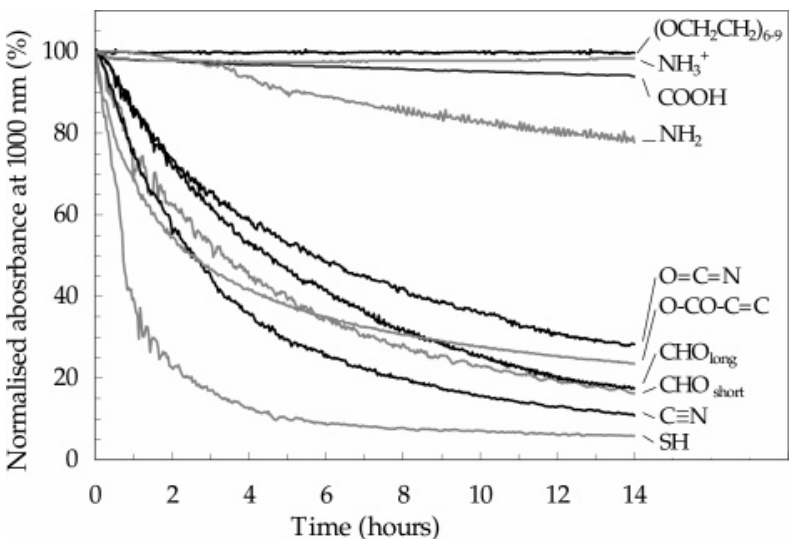

Figure 3. Colloidal stability of the silane-modified magnetic nanoparticles in water. The change of absorbance intensity (in terms of percentage) is monitored for $14 \mathrm{~h}$ at a fixed wavelength of $1000 \mathrm{~nm}$. The different endgroups of the applied silanes are indicated next to the curves.

nanoparticles' surface. Furthermore, we have shown that the deposited silanes form a dense organic layer while presenting their chemical endfunctions to the surrounding liquid. It is well-understood that the dispersibility in polar and nonpolar liquids is determined by the interaction between the liquid and the nanoparticle functional groups. For example, nonpolar groups, such as $\mathrm{CH}_{3}$, are known to render nanoparticles dispersible in nonpolar liquids. On the other hand, when polar groups such as $\mathrm{COOH}$ and $\mathrm{NH}_{2}$ are introduced, nanoparticles can be made water-dispersible. To thoroughly investigate the influence of the silane endgroup on the water-dispersibility and -stability, we transferred all MNPs to water immediately after silane ligand exchange.

Only the MNPs with carboxylic acid-, amino, and PEGsilanes resulted in a clear and transparent dispersion, indicative of an excellent water-dispersibility. It has to be noted that for the amino-modified MNPs, trace amounts of acid were added to enhance their water-dispersibility. This effect of the $\mathrm{pH}$ will be further elucidated in the following paragraph. On the other hand, all other silane-modified MNPs gave evidence of an opaque solution in which aggregation could be clearly observed. To quantify the colloidal stability in aqueous suspensions, the absorbance of the brownish nanoparticle dispersion was monitored at a fixed wavelength for $14 \mathrm{~h}$ (Figure 3). If the silane-modified MNPs are not dispersible in water, they will rapidly aggregate and settle down at the bottom of the cuvette, which can be monitored by a decrease in the absorbance as a function of time (see Figure S6 in the Supporting Information). Figure 3 clearly indicates that only the $\mathrm{COOH}-, \mathrm{NH}_{2}-$, and PEG-modified MNPs showed high water-dispersibility. After $14 \mathrm{~h}$, only small changes $(<20 \%)$ could be observed, indicating an excellent stability during this time frame. In contrast, all other silanes showed a decrease of $60-90 \%$, indicative of poor water-dispersibility. To evaluate their long-term stability and water-dispersibility, the $\mathrm{COOH}-, \mathrm{NH}_{2}$, and PEG-modified MNPs were stored at $4{ }^{\circ} \mathrm{C}$ for a period of 6 months and still the solution remained transparent without any sign of aggregation (data not shown). This same long-term stability could not be achieved for oleic-acid-stabilized MNPs in hexane, as they started to aggregate after approximately $2-3$ months. This enhanced stability is attributed to the strong 
covalent linkage of the silanes to the nanoparticles' surface compared to the chemisorbed oleic acid coating, which is more easily removed from the surface. ${ }^{50}$ These observations are in good agreement with the TGA data from the previous section. Again, it has to be noted that the amino-modified MNPs showed an increased water-dispersibility when trace amounts of acid were added, which converts the $\mathrm{NH}_{2}$ groups to their protonated, acidic $\mathrm{NH}_{3}{ }^{+}$form (Figure 3).

Table 2 gives an overview of water contact angles reported in the literature for self-assembled monolayers bearing identical endgroups, as used in this study. The most hydrophobic endgroup $\left(\mathrm{CH}_{3}\right)$, with a water contact angle of $\sim 110^{\circ}$, guarantees excellent dispersibility of the corresponding MNPs in nonpolar solvents. On the other hand, when the water contact angle was less than $\sim 40^{\circ}\left(\mathrm{NH}_{3}{ }^{+}, \mathrm{COOH}\right.$, and PEG), the nanoparticles could be easily dispersed in aqueous solutions because of their hydrophilic character. ${ }^{54}$ Endgroups with contact angles between 40 and $110^{\circ}$ form corresponding nanoparticles that could not be dispersed in nonpolar and polar solutions. These findings support the idea that surface hydrophilicity plays a pivotal role in creating water-dispersible nanoparticles. Apart from hydrophilicity, other factors are known to influence the water-dispersibility of nanoparticles. In the case of PEG endgroups, nanoparticles are also stabilized by the so-called steric repulsion. On the other hand, when the charged amino or carboxylic acid endgroups are present, the nanoparticles are also stabilized via electrostatic repulsion. These findings are in good agreement with present theories concerning colloidal stability and support the idea of a hydrophilic colloid, which is further stabilized via steric or electrostatic repulsion. ${ }^{54}$ These stabilization effects will be further elucidated in the following section. All other endgroups reported in Table 2 did not allow water-dispersibility because they did not present sufficient repulsive forces.

Characterization of Water-Dispersible Magnetic Nanoparticles. In this paragraph, we will further elucidate on the magnetic, morphological, and surface properties of the waterdispersible MNPs in comparison to the oleic-acid-stabilized MNPs. TEM micrographs of the MNPs before and after ligand exchange with $\mathrm{NH}_{2}-\mathrm{COOH}-$, and PEG-silanes are shown in Figure 4. The diameter and polydispersity calculated by averaging over more than 50 MNPs is summarized in Table 3. The oleic-acid-stabilized MNPs show high uniformity in size and shape with an average diameter of $8.6 \pm$ $1.3 \mathrm{~nm}$ (Figure 4A). On the basis of these images, the polydispersity is calculated to be $\sim 15 \%$. After silane ligand exchange, the MNPs maintained their original spherical shapes without any significant deformation or growth (Figure 4BD). This observation confirms that the modification takes place only at the nanoparticles' surface. After surface modification, the nanoparticles were found to be well-separated on the grid, without any sign of aggregation, reflecting their efficient silane coating and an excellent water-dispersibility. Furthermore, all TEM images show that the MNPs are single crystalline with a lattice spacing of $\sim 3.0 \AA$, corresponding to the (220) planes in spinel-structured $\mathrm{CoFe}_{2} \mathrm{O}_{4} \cdot{ }^{12,13}$

(54) Molina-Bolívar, J. A.; Ortega-Vinuesa, J. L. Langmuir 1999, 15, 2644.

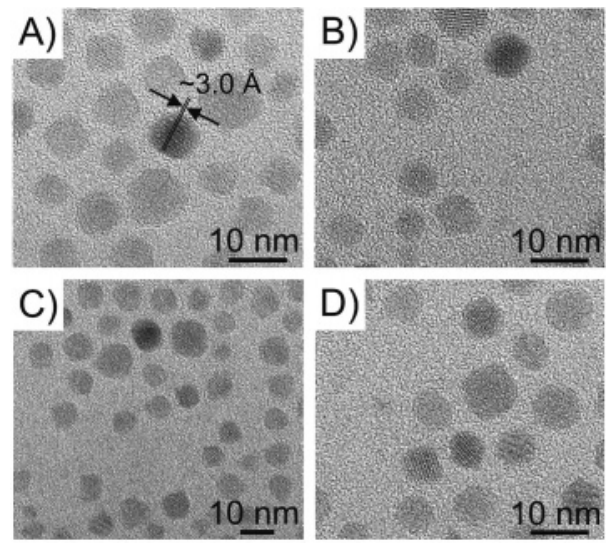

Figure 4. TEM images of the magnetic nanoparticles (a) before and (bd) after modification with silanes. Only the three silanes that resulted in water-dispersible nanoparticles are shown; (b) modified with poly(ethylene glycol)-silane, (c) modified with amino-silane, (d) modified with carboxylic acid-silane.

TEM has the major disadvantage that it can give information only on the inorganic ferrite core and that it cannot be used to gather information on the organic silane coating, because thin organic materials are usually transparent for TEM observation (Figure 4). To further investigate the influence of the silane ligand exchange on the overall size of the MNPs (inorganic core + organic coating), we performed DLS measurements (Table 3). DLS cannot discriminate between inorganic and organic material and thus measures the overall particle size. Therefore, the diameter determined via DLS is generally considered to be higher than that calculated via TEM. ${ }^{39}$ In the case of oleic-acid-stabilized MNPs the overall particle size is $9.4 \pm 2.9 \mathrm{~nm}$. The increased value compared to TEM can be explained by oleic acid, present as a continuous monolayer around each nanoparticle. After silane ligand exchange, a remarkable increase in overall particle size is observed to approximately $12-14 \mathrm{~nm}$, which indicates the successful deposition of a silane layer on the nanoparticles' surface. On the basis of DLS, we concluded that the $\mathrm{NH}_{2}$-silane forms the thickest coating, followed by $\mathrm{COOH}$ and PEG. These observations are in good agreement with the thicknesses calculated via XPS and the percentage of organic coating determined via TGA and therefore support the idea of a polymerized silane multilayer. Only one peak in the size distribution could be observed before and after ligand exchange, indicating the absence of aggregated species. This supports our findings that $\mathrm{NH}_{2}, \mathrm{COOH}-$, and PEGsilanes give rise to a single particle coated by a silane layer, rather than a group of particles encapsulated in a silane matrix. At the same time, it proves the excellent water-dispersibility and colloidal stability of our silane-modified MNPs, which was attributed to the presence of repulsive forces between the single particles, thereby limiting their aggregation.

Figure 5 shows a plot of the zeta potential vs the $\mathrm{pH}$ for the $\mathrm{NH}_{2^{-}}, \mathrm{COOH}-$, and PEG-modified MNPs. For the oleic acid stabilized MNPs, the zetapotential could not be measured as a function of the $\mathrm{pH}$ because they are solely dispersible in organic solvents. Zeta potential measurements allow us to determine the charge of the nanoparticles in different environments and calculate the isoelectric point (pI), which is the $\mathrm{pH}$ at which there is no charge on the nanoparticles' surface (Table 3). The presence of positive 
Table 3. Particle Diameter Determined via TEM and DLS for Oleic-Acid-Stabilized Magnetic Nanoparticles in Hexane and for Silane-Modified Magnetic Nanoparticles, Containing Carboxylate, Amino, and Poly(ethylene Glycol) Endgroups, in Water ${ }^{a}$

\begin{tabular}{|c|c|c|c|c|c|c|c|c|}
\hline \multirow[b]{2}{*}{$\mathrm{CoFe}_{2} \mathrm{O}_{4}$ modification } & \multirow[b]{2}{*}{ dispersed in } & \multicolumn{2}{|c|}{ diameter (nm) } & \multirow[b]{2}{*}{$\mathrm{pH}^{b}$} & \multirow[b]{2}{*}{$\mathrm{pI}$} & \multirow[b]{2}{*}{ magnetic content $(\%)^{c}$} & \multicolumn{2}{|c|}{$\mathrm{M}_{\mathrm{s}}(\mathrm{emu} / \mathrm{g}$ particles $)$} \\
\hline & & TEM & DLS & & & & SQUID & $\mathrm{TGA}^{d}$ \\
\hline $\mathrm{CoFe}_{2} \mathrm{O}_{4}+$ oleic acid & hexane & $8.6 \pm 1.3$ & $9.4 \pm 2.9$ & & & 85.1 & 69.1 & 67 \\
\hline $\mathrm{CoFe}_{2} \mathrm{O}_{4}+\mathrm{PEG}$ & $\mathrm{H}_{2} \mathrm{O}$ & $8.4 \pm 1.5$ & $12.2 \pm 2.7$ & 6.3 & 8.7 & 25 & 22.7 & 20 \\
\hline $\mathrm{CoFe}_{2} \mathrm{O}_{4}+\mathrm{NH}_{2}$ & $\mathrm{H}_{2} \mathrm{O}$ & $8.7 \pm 1.3$ & $14.4 \pm 2.8$ & 10.4 & 10.4 & 28.4 & 22.4 & 22 \\
\hline $\mathrm{CoFe}_{2} \mathrm{O}_{4}+\mathrm{COOH}$ & $\mathrm{H}_{2} \mathrm{O}$ & $8.2 \pm 1.2$ & $13.5 \pm 2.0$ & 11.3 & 3.1 & 21.6 & 15.7 & 17 \\
\hline
\end{tabular}

${ }^{a}$ The $\mathrm{pH}$ and isoelectric point $(\mathrm{pI})$ are also tabulated, as well as the magnetic content determined via TGA. The saturation magnetization $\left(M_{\mathrm{s}}\right)$ was measured using SQUID and compared to values calculated on the basis of TGA Data. ${ }^{b}$ For a dispersion of particles in D.I. water at $\sim 1 \mathrm{mg} / \mathrm{mL} .{ }^{c}$ Magnetic content $=100 \%$ - weight loss $(\%)$ determined via TGA ${ }^{d}$ Calculated from magnetic content determined via TGA and assuming a saturation magnetization $\left(M_{\mathrm{s}}\right)$ of $79 \mathrm{emu} / \mathrm{g}$ for uncoated $\mathrm{CoFe}_{2} \mathrm{O}_{4}$ particles (14) (see eq 3).

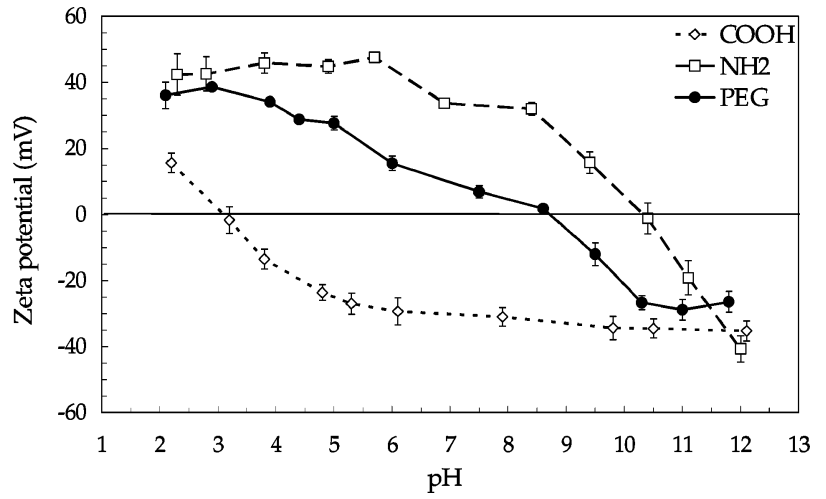

Figure 5. Zeta potential vs $\mathrm{pH}$ for the water dispersible silane-modified magnetic nanoparticles (with carboxylic acid, poly(ethylene glycol), or amino endgroups).

or negative charges can be identified by a positive or negative zeta potential. respectively. The higher the zeta potential, the more charges are present on the nanoparticles' surface. For $\mathrm{COOH}$-modified MNPs, the isoelectric point was observed at pH 3.1 (Figure 5), which is expected on the basis of the acidity of carboxylic acids. The low $\mathrm{pI}$ implicates that the $\mathrm{COOH}$-modified MNPs present carboxylate functions $\left(\mathrm{COO}^{-}\right)$on their surface and are thus negatively charged over almost the entire $\mathrm{pH}$ range. This is supported by FTIR and XPS data, for which the presence of carboxylate functions could also be identified. The amino functions, on the other hand, exhibit a pI of 10.4 (Table 3), which imparts a continuous positive charge over the entire lower $\mathrm{pH}$ range (Figure 5) due to the presence of $\mathrm{NH}_{3}{ }^{+}$groups. This pI is in good agreement with the basic character of amino functions. Finally, the PEG-modified MNPs exhibited an isoelectric point at $\mathrm{pH}$ 6.3. At higher $\mathrm{pH}$, the particles become negatively charged, whereas at lower $\mathrm{pH}$, they become more positive (Figure 5). This is rather unexpected, because PEG does not contain any acidic or basic endfunctions. One possible explanation could be the uptake of ions in the PEG layer when $\mathrm{HCl}$ or $\mathrm{NaOH}$ were used as titrants. Similar observations of ion uptake in PEG layers have been made before by Kreuzer et al. ${ }^{55}$

These findings play an important role in understanding the stability of our silane-modified MNPs. During $\mathrm{pH}$ titration, one can visually observe aggregation, which gives an idea on the stability of the silane-modified nanoparticles as a function of the $\mathrm{pH}$. For PEG-modified MNPs, no aggregation could be observed in the range of $2<\mathrm{pH}<$

(55) Kreuzer, H. J.; Wang, R. L.; Grunze, M. J. Am. Chem. Soc. 2003, 125,8384 .
12. Even around its isoelectric point, the PEG-modified MNPs remained perfectly stable. This result confirms that PEG imparts stability to the MNPs by steric interactions rather than via electrostatic repulsions. On the other hand, for carboxylic acid- and amino-modified MNPs, it was observed that the nanoparticles started to aggregate when the $\mathrm{pH}$ was close to the isoelectric point. For $\mathrm{COOH}$ and $\mathrm{NH}_{2}$, strong aggregation was observed, respectively, in the range of $2<\mathrm{pH}<5$ and $9<\mathrm{pH}<11$. In both cases, the zeta potential was observed to be less than $\sim 30 \mathrm{mV}$, which is generally considered as the threshold value for electrostatic stabilization. ${ }^{56}$ The aggregation close to the $\mathrm{pI}$ can be understood by the low amount of repulsive charges and consequently the attractive van der Waals interactions will lead to aggregation. These findings implicate that $\mathrm{COOH}-$ and $\mathrm{NH}_{2}$-modified MNPs are mainly stabilized by electrostatic repulsions and surface hydrophilicity and probably not by steric repulsion. Table 3 shows the $\mathrm{pH}$ of the nanoparticles dispersed in D.I. water. In the case of PEG and $\mathrm{NH}_{2}$, the $\mathrm{pH}$ of the dispersion is as expected for a neutral $(\mathrm{pH}$ 6.3) and an alkaline ( $\mathrm{pH}$ 10.4) functionality, respectively. For $\mathrm{COOH}-$ modified MNPs, on the other hand, we observed a highly alkaline dispersion ( $\mathrm{pH}$ 11.3), which is in contrast to the acidity of the $\mathrm{COOH}$ function. Until now, no valid explanation for this phenomenon could be recognized.

It also has to be noted that the silane-modified MNPs did not disintegrate at extreme $\mathrm{pH}$ values as compared to oleicacid-stabilized MNPs, in which immediate disintegration in the presence of $\mathrm{HCl}$ was observed. This enhanced resistance against acid and alkaline environments confirms our conclusion that the silanes form a densely packed protective layer that does not allow penetration of acids and alkalines. Consequently, the ferrite core cannot be etched, which

(56) Cunningham, D.; Littleford, R. E.; Smith, W. E.; Lundahl, P. J.; Khan, I.; McComb, D. W.; Graham, D.; Laforest, N. Faraday Discuss. 2006, $132,135-145$.

(57) Tillman, N.; Ulman, A.; Schildkraut, J. S.; Penner, T. L. J. Am. Chem. Soc. 1988, 110, 6136.

(58) Balachander, N.; Sukenik, C. N. Langmuir 1990, 6, 1621.

(59) Falipou, S.; Chovelon, J.-M.; Martelet, C.; Margonari, J.; Cathignol, D. Bioconjugate Chem. 1999, 10, 346.

(60) Delorme, N.; Bardeau, J.-F.; Bulou, A.; Poncin-Epaillard, F. Langmuir 2005, 21, 12278.

(61) Sapsford, K. E.; Ligler, F. S. Biosens. Bioelectron. 2004, 19, 1045.

(62) Rozkiewicz, D. I.; Ravoo, B. J.; Reinhoudt, D. N. Langmuir 2005 $21,6337$.

(63) Sorribas, H.; Padeste, C.; Tiefenauer, L. Biomaterials 2002, 23, 893

(64) Papra, A.; Gadegaard, N.; Larsen, N. B. Langmuir 2001, 17, 1457.

(65) Wu, B.; Mao, G.; Simon, K. Y. Colloids Surf., A 2000, 162, 203.

(66) Troughton, E. B.; Bain, C. D.; Whitesides, G. M.; Nuzzo, R. G.; Allara, D. L.; Porter, M. D. Langmuir 1988, 4, 365.

(67) Janssen, D.; De Palma, R.; Verlaak, S.; Heremans, P.; Dehaen, W. Thin Solid Films 2006, 515, 1433-1438. 


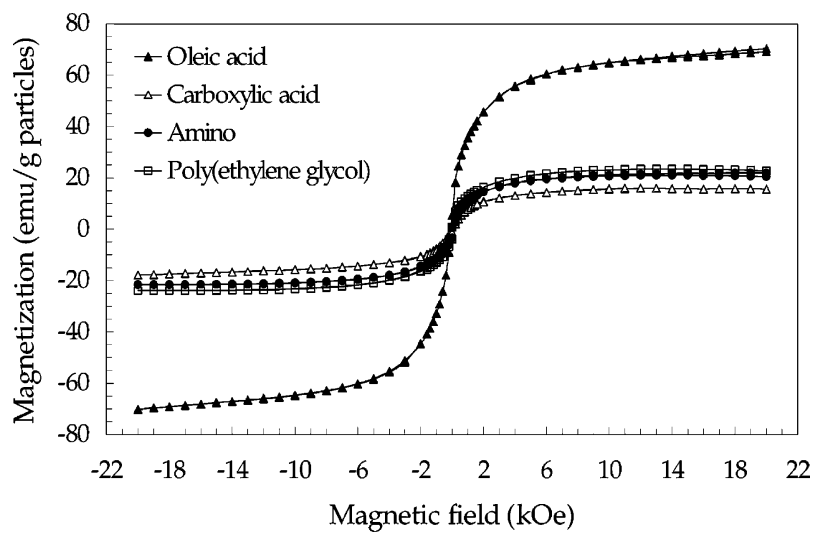

Figure 6. Hysteresis cycle of the magnetization for oleic-acid-stabilized magnetic nanoparticles in hexane and silane-modified magnetic nanoparticles, containing carboxylic acid, amino, and poly(ethylene glycol) endgroups, in water.

enhances the stability of these nanoparticles in mild acid or alkaline environments.

On the basis of TGA measurements (Table 2), we could also study the influence of the silane ligand exchange on the magnetic content per particle (Table 3 ). In the case of MNPs consisting out of an inorganic magnetic core and an organic nonmagnetic shell, the magnetic content can be calculated from the percentage of organic coating. The high magnetic content (85\%) for oleic-acid-stabilized MNPs supports the presence of a thin monolayers of ligands, as observed via XPS and DLS. By applying a silane coating, the magnetic content per particle was found to decrease significantly to $\sim 25 \%$. This can be attributed to the presence of a polymerized multilayer of silane ligands as observed before via XPS and TGA.

To study the magnetic behavior before and after silane ligand exchange, magnetization measurements were performed using SQUID. The magnetization curve for the oleicacid-stabilized MNPs showed no hysteresis and was completely reversible at $300 \mathrm{~K}$ (Figure 6). Neither coercivity nor remanence was observed. The MNPs exhibited a typical superparamagnetic behavior, a property that is in agreement with what should be expected from their particle size. ${ }^{12}$ Their superparamagnetic character was further confirmed by a fitting of the hysteresis curve to the Langevin function (Figure 6). After silane ligand exchange, the particles retained their superparamagnetic behavior giving proof that the particles' magnetic properties are not affected by the introduction of a silane layer. Another important parameter that can be derived from a hysteresis curve is the saturation magnetization $\left(M_{\mathrm{s}}\right.$; Table 3$)$. The $M_{\mathrm{s}}$ value could also be estimated on the basis of TGA data via the following formula (Table 3)

$$
M_{\mathrm{s}}=M_{\mathrm{s}}^{\mathrm{CoFe}_{2} \mathrm{O}_{4}}(100-\omega)
$$

where $M_{\mathrm{s}}^{\mathrm{CoFe}_{2} \mathrm{O}_{4}}$ is the theoretical saturation magnetization for $\mathrm{CoFe}_{2} \mathrm{O}_{4}$ nanoparticles $(\sim 79 \mathrm{emu} / \mathrm{g})^{12}$ and $\omega$ is the mass loss (\%) determined via TGA. Table 3 shows a great loss of magnetization per gram of particles when silane layers were applied. This loss can be designated to the introduction of a nonmagnetic mass (i.e., silane layer) onto the nanoparticles' surface. These finding are validated by the excellent agree- ment between the saturation magnetization measured via SQUID and calculated via TGA. Furthermore, the high loss of magnetization found after silane ligand exchange supports our idea that the silanes form a rather polymerized multilayer, whereas oleic acid is instead present as a monolayer.

\section{Conclusion}

In this paper, we have indicated that silane self-assembly can be successfully applied to exchange the original hydrophobic oleic acid ligand from the surface of ferrite nanoparticles without altering the nanoparticles' morphology. Furthermore, the modified MNPs were thoroughly characterized using a variety of complementary techniques, to get a better understanding on how the MNPs are altered by the silane ligand exchange reaction. By this means, we have shown that all types of silanes can be deposited on the surface of ferrite MNPs and that they form a presumably polymerized multilayer while presenting their chemical endfunctions to the surrounding liquid. It was shown that the presence of these endgroups strongly determines the water-dispersibility of the nanoparticles. $\mathrm{NH}_{2}, \mathrm{COOH}$, and PEG were found to render these nanoparticles dispersible in aqueous solutions over a wide $\mathrm{pH}$ range. In general, these coatings can be described as being positively charged, negatively charged, and neutral, respectively. It was recognized that surface hydrophilicity, in combination with electrostatic and steric repulsions, play an important role in the stabilization of MNPs. Compared to other ligands commonly used to stabilize ferrite MNPs, we observed an enhanced long-term stability and an increased resistance against mild acid and alkaline environments. This was attributed to the covalent linkage of the silane layers onto the nanoparticles' surface. Finally, we can conclude that the silane ligand exchange described in this paper represents a generic and versatile method for synthesizing highly stable, water-dispersible ferrite MNPs with a tunable ligand periphery. In future research and applications, the variety of endgroups can be exploited to allow for controlled interactions with biological moieties, such as proteins, DNA, or cells. From this study, we believe that silane-modified MNPs can be excellent candidates for successful application in a wide variety of biological applications.

Acknowledgment. R.D.P. is grateful to the "Instituut voor de Bevordering van het Wetenschappelijk en Technologisch onderzoek in Vlaanderen (IWT)" for its financial support. The authors also thank Dr. Thierry Conard and Ilse Hoflijk for the XPS measurements, Riet Labie for her help during EDX analysis, and Alessandro Benedetti for acquiring the TEM images.

Supporting Information Available: FTIR spectra of the magnetic nanoparticles before and after modification with silanes; XPS survey spectra, deconvoluted O1s subregions, and deconvoluted S2p, N1s, Si2p, and Fe2p subregions of unmodified and silanemodified magnetic nanoparticles; EDX spectrum for cobalt ferrite magnetic nanoparticles; monitoring of the UV-vis absorbance for $14 \mathrm{~h}$ to evaluate the colloidal stability of the silane-modified magnetic nanoparticles in water. This material is available free of charge via the Internet at http://pubs.acs.org.

CM0628000 


\section{Supporting information}

for

\section{Silane Ligand Exchange to Make Hydrophobic Superparamagnetic Nanoparticles Water-Dispersible}

Randy De Palma, Sara Peeters, Margriet J. Van Bael, Heidi Van den Rul, Kristien Bonroy, Wim Laureyn, Jules Mullens, Gustaaf Borghs, Guido Maes

Figure S1. FTIR spectra of the magnetic nanoparticles (a) before and (b-j) after modification with silanes. (a) oleic acid stabilized, modified with (b) cyano-silane, (c) isocyanate-silane, (d) acrylate-silane, (e) thiol-silane, (f) short aldehyde-silane, (g) long aldehyde-silane, (h) poly(ethylene glycol)-silane, (i) amino-silane, (j) carboxylic acid-silane.

Figure S2. XPS survey spectrum of oleic acid stabilized magnetic nanoparticles and magnetic nanoparticles modified with amino-silane.

Figure S3. Deconvoluted high-resolution XPS spectra of the O1s subregion for unmodified (oleic acid) and silane-modified magnetic nanoparticles.

Figure S4. A selection of high-resolution spectra of the S2p, N1s, Si2p and Fe2p subregions for oleic acid stabilized and silane-modified magnetic nanoparticles. For Si2p and Fe2p only one spectrum is shown, all others were found to be identical.

Figure S5. EDX spectrum for cobalt ferrite magnetic nanoparticles. The spectrum is only shown for oleic acid stabilized nanoparticles, but it was found to be identical after silanemodification. Inset shows the atomic percentages of $\mathrm{Co}$ and $\mathrm{Fe}$ leading to $\mathrm{Co}_{0.8} \mathrm{Fe}_{2.2} \mathrm{O}_{4}$.

Figure S6. UV-vis absorbance spectrum for magnetic nanoparticles modified with a short aldehydesilane. The absorbance at $1000 \mathrm{~nm}$ was monitored as a function of time during 14 hours to evaluate the colloidal stability of the silane-modified magnetic nanoparticles in water. All other silane-modified magnetic nanoparticles were measured by the same procedure. 
Figure S1. FTIR spectra of the magnetic nanoparticles (a) before and (b-j) after modification with silanes. (a) oleic acid stabilized, modified with (b) cyano-silane, (c) isocyanate-silane, (d) acrylatesilane, (e) thiol-silane, (f) short aldehyde-silane, (g) long aldehyde-silane, (h) poly(ethylene glycol)silane, (i) amino-silane, (j) carboxylic acid-silane.

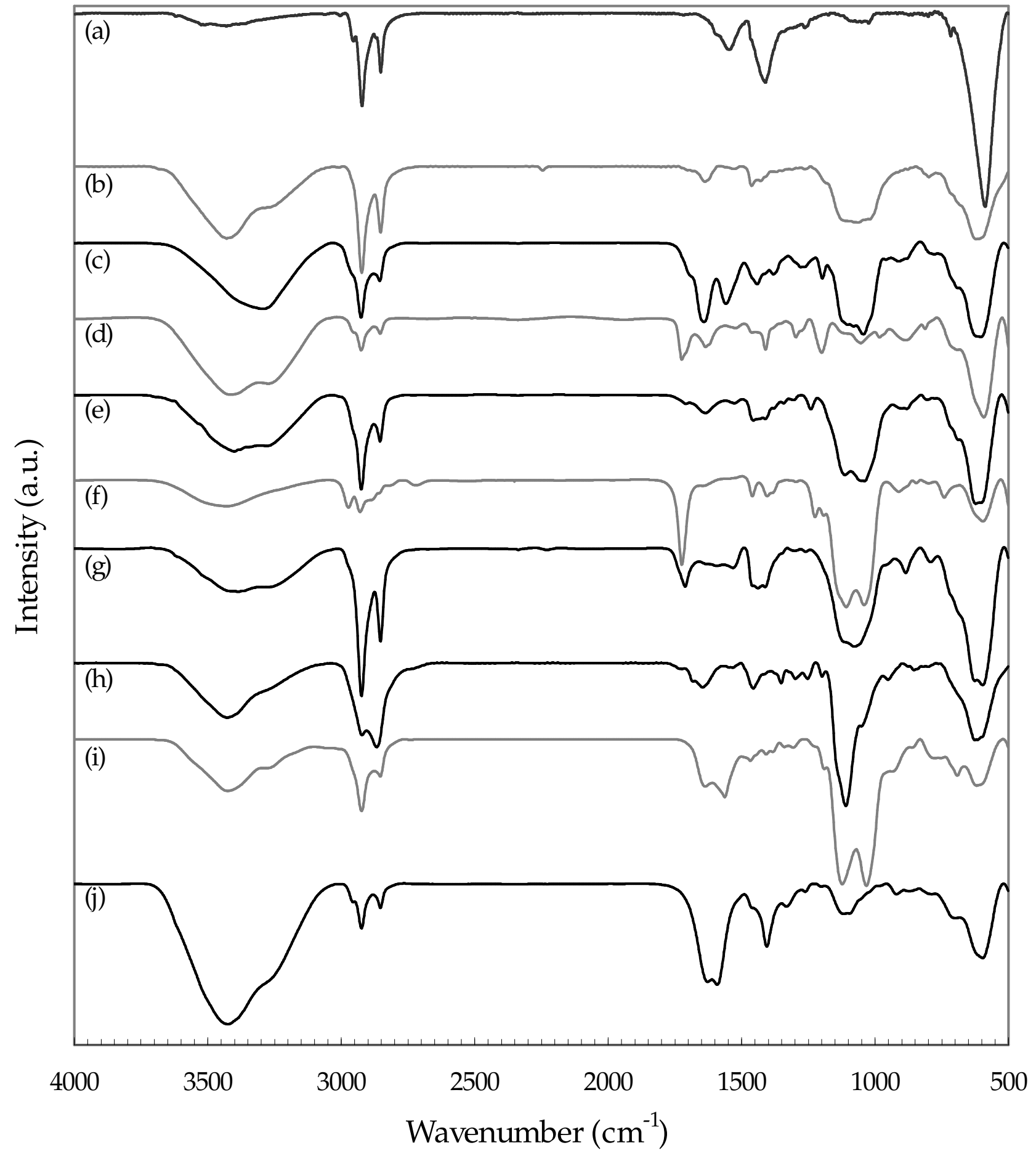


Figure S2. XPS survey spectrum of oleic acid stabilized magnetic nanoparticles and magnetic nanoparticles modified with amino-silane.

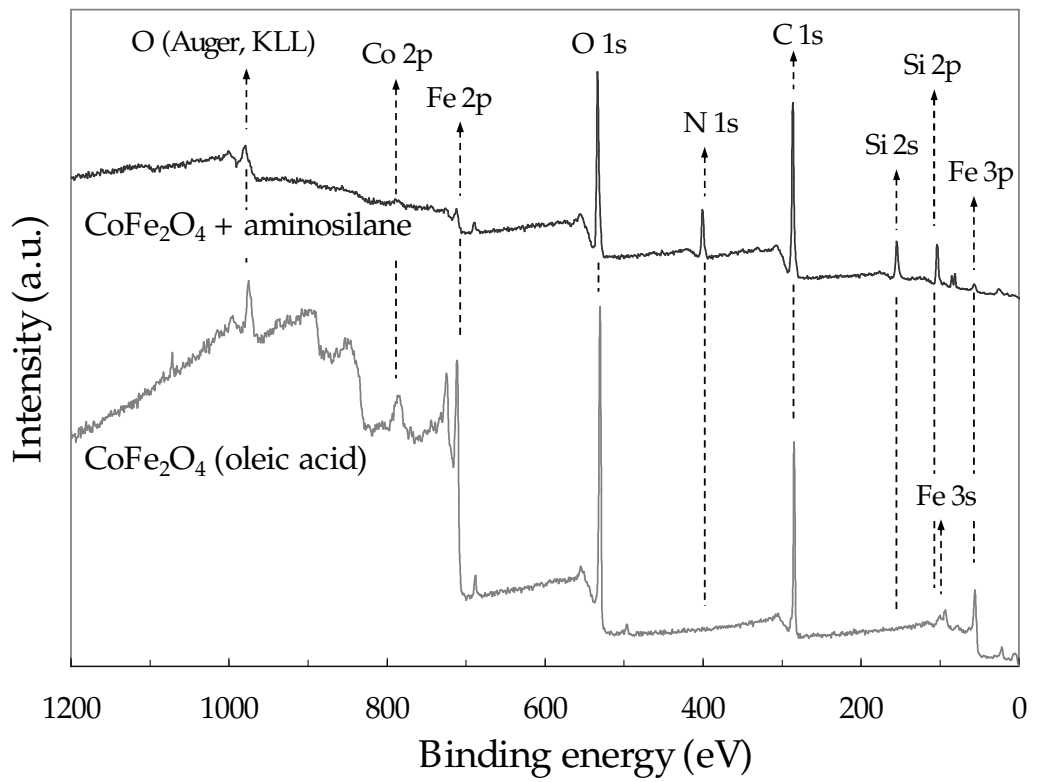

Figure S3. Deconvoluted high-resolution XPS spectra of the O1s subregion for unmodified (oleic acid) and silane-modified magnetic nanoparticles.
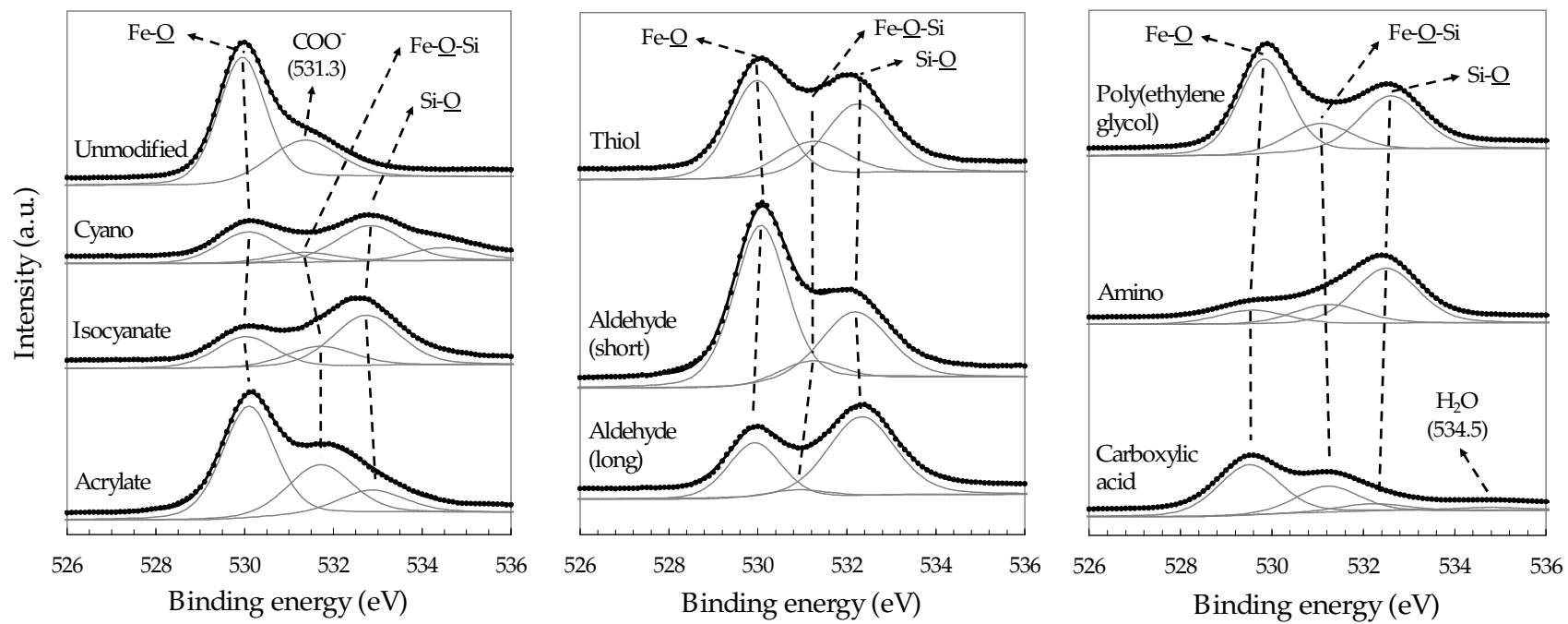
Figure S4. A selection of high-resolution spectra of the S2p, N1s, Si2p and Fe2p subregions for oleic acid stabilized and silane-modified magnetic nanoparticles. For Si2p and Fe2p only one spectrum is shown, all others were found to be identical.
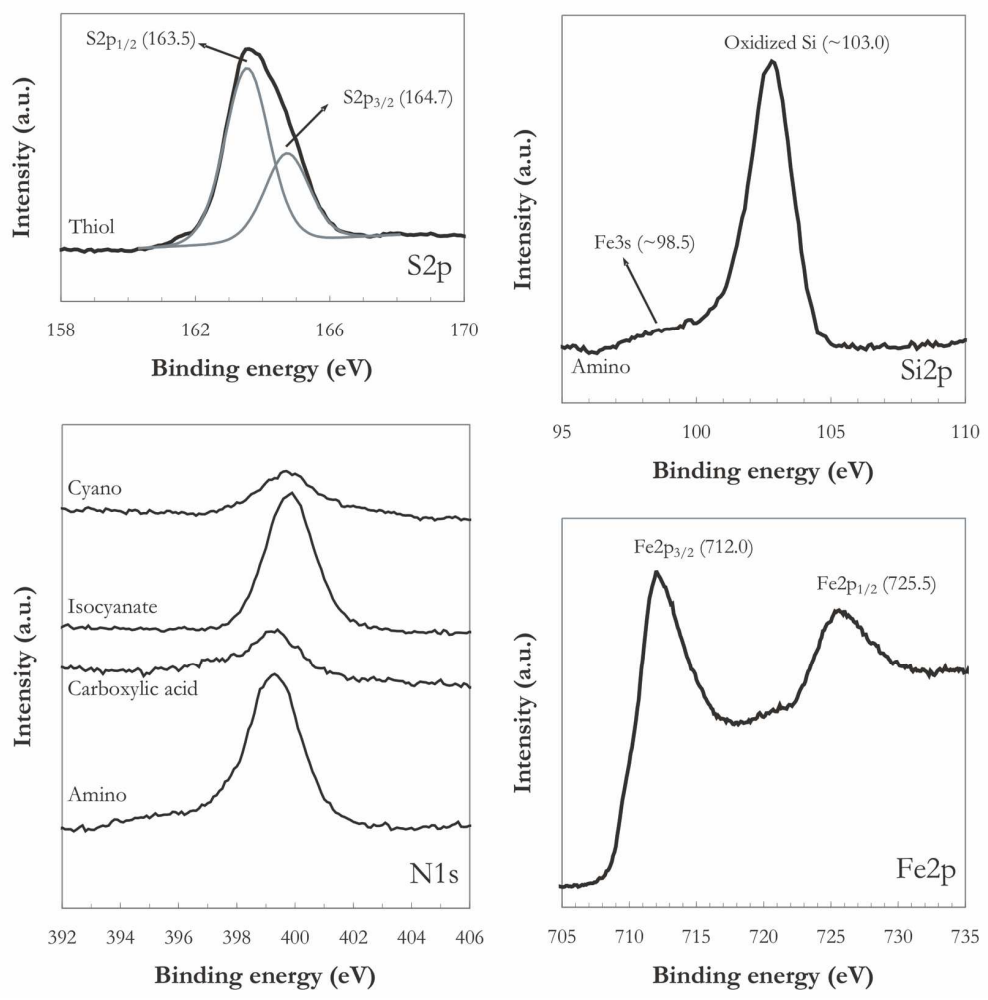

Figure S5. EDX spectrum for cobalt ferrite magnetic nanoparticles. The spectrum is only shown for oleic acid stabilized nanoparticles, but it was found to be identical after silane-modification. Inset shows the atomic percentages of $\mathrm{Co}$ and $\mathrm{Fe}$ leading to $\mathrm{Co}_{0.8} \mathrm{Fe}_{2.2} \mathrm{O}_{4}$.

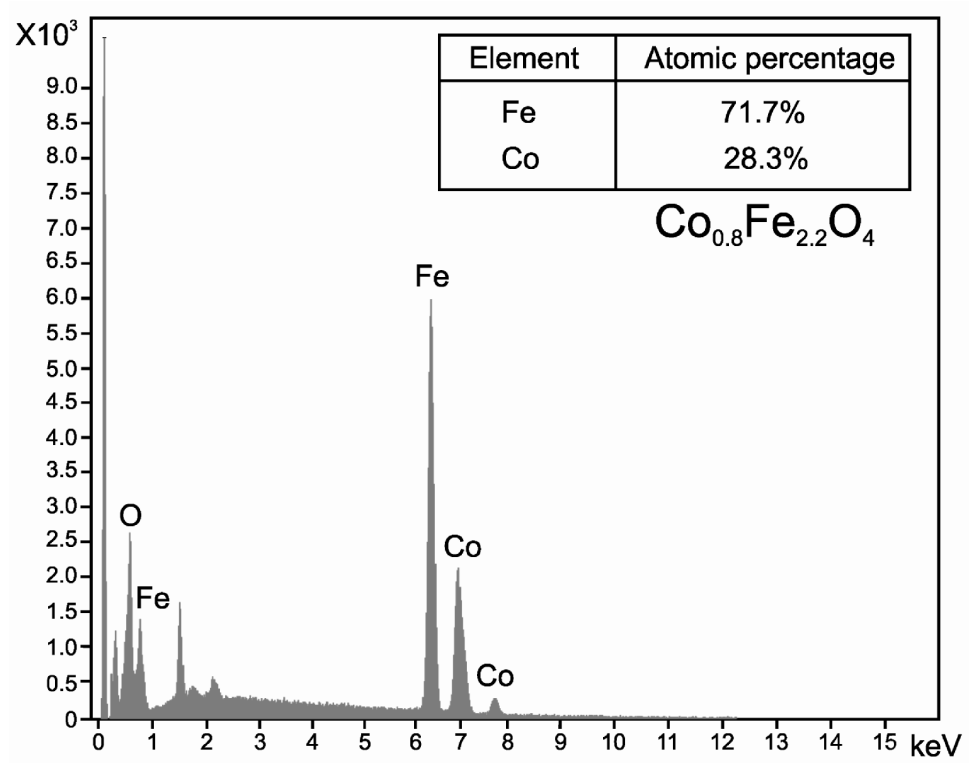


Figure S6. UV-vis absorbance spectrum for magnetic nanoparticles modified with a short aldehydesilane. The absorbance at $1000 \mathrm{~nm}$ was monitored as a function of time during 14 hours to evaluate the colloidal stability of the silane-modified magnetic nanoparticles in water. All other silane-modified magnetic nanoparticles were measured by the same procedure.

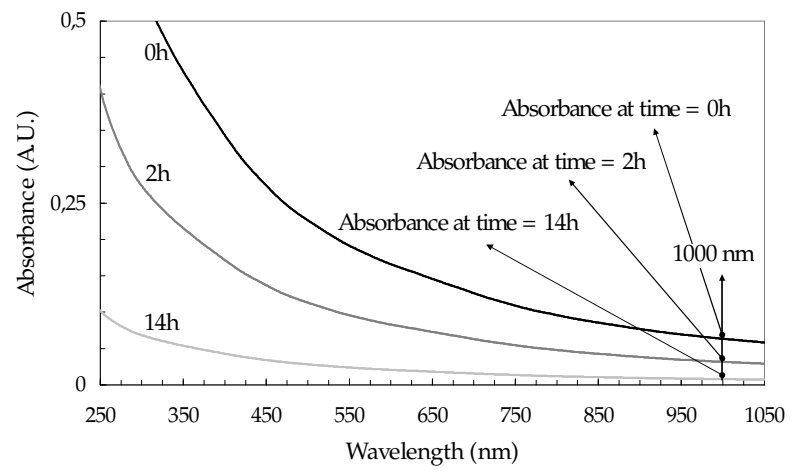

